\title{
A Review of Water Isotopes in Atmospheric General Circulation Models: Recent Advances and Future Prospects
}

\author{
Xi Xi \\ Environmental Science and Engineering, California Institute of Technology, 1200 East California Boulevard, MC 150-21, \\ Pasadena, CA, USA \\ Correspondence should be addressed to Xi Xi; xixi@caltech.edu
}

Received 1 June 2014; Revised 23 July 2014; Accepted 24 July 2014; Published 24 September 2014

Academic Editor: Helena A. Flocas

Copyright (c) $2014 \mathrm{Xi} \mathrm{Xi}$. This is an open access article distributed under the Creative Commons Attribution License, which permits unrestricted use, distribution, and reproduction in any medium, provided the original work is properly cited.

\begin{abstract}
Stable water isotopologues, mainly ${ }^{1} \mathrm{H}_{2} \mathrm{O},{ }^{1} \mathrm{H}^{2} \mathrm{HO}(\mathrm{HDO})$, and ${ }^{1} \mathrm{H}_{2}{ }^{18} \mathrm{O}$, are useful tracers for processes in the global hydrological cycle. The incorporation of water isotopes into Atmospheric General Circulation Models (AGCMs) since 1984 has helped scientists gain substantial new insights into our present and past climate. In recent years, there have been several significant advances in water isotopes modeling in AGCMs. This paper reviews and synthesizes key advances accomplished in modeling (1) surface evaporation, (2) condensation, (3) supersaturation, (4) postcondensation processes, (5) vertical distribution of water isotopes, and (6) spatial $\delta^{18} \mathrm{O}$-temperature slope and utilizing (1) spectral nudging technique, (2) higher model resolutions, and (3) coupled atmosphereocean models. It also reviews model validation through comparisons of model outputs and ground-based and spaceborne measurements. In the end, it identifies knowledge gaps and discusses future prospects of modeling and model validation.
\end{abstract}

\section{Introduction}

Stable water isotopologues, mainly ${ }^{1} \mathrm{H}_{2} \mathrm{O},{ }^{1} \mathrm{H}^{2} \mathrm{HO}$ (HDO), and ${ }^{1} \mathrm{H}_{2}^{18} \mathrm{O}$, differ by their mass and molecular symmetry. As a result, during phase transitions, they have slightly different behaviors. The heavier molecules prefer to stay in the liquid or solid phase while the lighter ones tend to evaporate more easily. This unique characteristic makes water isotopologues the ideal tracers for processes in the global hydrological cycle. In the past three decades, the incorporation of water isotopes into Atmospheric General Circulation Models (AGCMs) has helped scientists gain substantial new insights into our present and past climate.

AGCMs (or more generally, GCMs) numerically represent our current understanding of the physical processes in the atmosphere on a rotating planet. They usually contain main modules for advection, diffusion, convection, radiation, cloud formation, and other physics. Much effort has been put into model development to ensure numerical simulations do reflect our physical understanding of the atmosphere. In addition to model development, model validation with realworld data is of paramount importance because it ensures that what is simulated are real physical phenomena in nature, not artifacts caused by inadequate model parameterizations. Only after AGCMs are validated with global measurements of water isotopes could they be deployed with confidence to address new scientific questions such as changes in the global precipitation patterns and large-scale atmospheric circulations.

When Hoffmann et al. [1] published their review on water isotopes in GCMs, they tabulated ten published studies on isotope modeling, seven of which were on present-day climate. The most recent review is by Sturm et al. [2], which provides an introduction to stable water isotopes in climate models and focuses on paleoclimate studies. In the past thirteen years, empowered by more expertise and computational resources, the isotope modeling community has blossomed. At last count, there are almost a dozen isotope-enabled models of various scales developed worldwide (see Table 1 and [3]). There have been several significant advances in water isotopes modeling in AGCMs. It is thus an opportune time to look back at what has been collectively achieved by the modeling community. This paper aims to (1) review and synthesize recent advances of water isotopes modeling in AGCMs and model validation through comparisons of model outputs and ground-based and spaceborne measurements 
TABLE 1: Selected isotope-enabled AGCMs and their characteristics.

\begin{tabular}{|c|c|c|c|c|}
\hline $\begin{array}{l}\text { Isotope-enabled } \\
\text { AGCMs }\end{array}$ & References & Resolutions & Timestep & Input data \\
\hline $\begin{array}{l}\text { CAM2 } \\
\text { (Community } \\
\text { Atmosphere } \\
{\text { Model })^{1}}^{1}\end{array}$ & $\begin{array}{c}\text { Lee et al. [22] } \\
\text { Lee and Fung [27] }\end{array}$ & $\begin{array}{c}\sim 2.8^{\circ} \times 2.8^{\circ} \\
26 \text { vertical levels }\end{array}$ & 20 mins & $\begin{array}{l}\text { Free-running with } \\
\text { climatological } \\
\text { monthly mean SSTs }\end{array}$ \\
\hline ECHAM5-wiso $^{2}$ & Werner et al. [25] & $\begin{array}{c}\sim 3.8^{\circ} \times 3.8^{\circ} \\
19 \text { vertical levels } \\
(\text { adjustable })\end{array}$ & $\begin{array}{c}40 \text { mins } \\
\text { (adjustable to } \\
4 \text { mins) } \\
\end{array}$ & $\begin{array}{l}\text { Free-running with } \\
\text { climatological } \\
\text { monthly mean SSTs }\end{array}$ \\
\hline $\begin{array}{l}\text { GISS ModelE } \\
\text { (Goddard Institute } \\
\text { for Space Studies) }^{3} \\
\text { as known as GissE }\end{array}$ & $\begin{array}{l}\text { Schmidt et al. [58] } \\
\text { Schmidt et al. [31] }\end{array}$ & $\begin{array}{c}4^{\circ} \times 5^{\circ} \\
23 \text { vertical levels } \\
(\text { adjustable })\end{array}$ & $\begin{array}{c}0.5 \text { hrs } \\
\text { (adjustable) }\end{array}$ & $\begin{array}{l}\text { Nudged by reanalysis } \\
\text { or free-running }\end{array}$ \\
\hline $\begin{array}{l}\text { IsoGSM } \\
\text { (Isotope- } \\
\text { incorporated } \\
\text { Global Spectral } \\
\text { Model) }\end{array}$ & $\begin{array}{l}\text { Yoshimura et al. [32] } \\
\text { Yoshimura et al. [29] }\end{array}$ & $\begin{array}{c}1.85^{\circ} \times 1.85^{\circ} \\
17 \text { vertical levels }\end{array}$ & $\mathrm{NA}^{6}$ & $\begin{array}{l}\text { Nudged by reanalysis } \\
\text { (designed for spectral } \\
\text { nudging) }\end{array}$ \\
\hline $\begin{array}{l}\text { HadCM3 } \\
\text { (Hadley Centre } \\
\text { Coupled Model, } \\
\text { V3) }\end{array}$ & Tindall et al. [18] & $\begin{array}{c}2.5^{\circ} \times 3.75^{\circ} \\
19 \text { vertical levels }\end{array}$ & $0.5 \mathrm{hrs}$ & $\begin{array}{l}\text { free-running with } \\
\text { climatological } \\
\text { monthly mean SSTs }\end{array}$ \\
\hline $\begin{array}{l}\text { MIROC3.2 } \\
\text { (Model for } \\
\text { Interdisciplinary } \\
\text { Research on } \\
\text { Climate) } \\
\end{array}$ & Kurita et al. [49] & $\begin{array}{c}1.1^{\circ} \times 1.1^{\circ} \\
40 \text { vertical levels }\end{array}$ & 20 mins & $\begin{array}{l}\text { Run with } \\
\text { climatological } \\
\text { monthly mean SSTs, } \\
\text { nudged by horizontal } \\
\text { winds }\end{array}$ \\
\hline $\begin{array}{l}\text { MUGCM } \\
\text { (Melbourne } \\
\text { University GCM) }\end{array}$ & $\begin{array}{l}\text { Noone and } \\
\text { Simmonds [13] }\end{array}$ & $\begin{array}{l}3.25^{\circ} \times 5.625^{\circ} \\
9 \text { vertical levels }\end{array}$ & 20 mins & $\begin{array}{l}\text { Free-running with } \\
\text { climatological } \\
\text { monthly mean SSTs }\end{array}$ \\
\hline $\begin{array}{l}\text { LMDZ4 } \\
\text { (Laboratoire de } \\
\text { Météorologie } \\
\text { Dynamique) }\end{array}$ & $\begin{array}{l}\text { Hourdin et al. [59] } \\
\text { Risi [14] } \\
\text { Risi et al. [33] }\end{array}$ & $\begin{array}{c}\text { Standard } \\
2.5^{\circ} \times 3.75^{\circ} \\
19 \text { vertical levels }\end{array}$ & 3 mins & $\begin{array}{l}\text { Nudged by reanalysis } \\
\text { or free-running }\end{array}$ \\
\hline $\begin{array}{l}\text { GENESIS GCM } \\
\text { (Global } \\
\text { Environmental and } \\
\text { Ecological } \\
\text { Simulation of } \\
\text { Interactive } \\
\text { Systems) }\end{array}$ & Mathieu et al. [26] & $\begin{array}{c}\sim 3.75^{\circ} \times 3.75^{\circ} \\
18 \text { vertical levels }\end{array}$ & $0.5 \mathrm{hrs}$ & $\begin{array}{l}\text { Free-running with } \\
\text { climatological } \\
\text { monthly mean SSTs }\end{array}$ \\
\hline $\begin{array}{l}{ }^{1} \text { Another version of the } \\
{ }^{2} \text { Other versions of the } \mathrm{m} \\
{ }^{3} \text { Another version of the } \\
{ }^{4} \text { The coupled model con } \\
{ }^{5} \text { Another version of the } \\
{ }^{6} \text { NA stands for not avail }\end{array}$ & $\begin{array}{l}\text { CAM3. } \\
\text { ECHAM3 and ECHAM } \\
\text { GISS II. } \\
\text { imospheric component } \\
\text { LMD. }\end{array}$ & 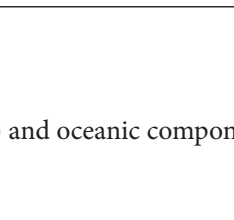 & & \\
\hline
\end{tabular}

and (2) identify knowledge gaps and discuss future prospects of modeling and model validation.

Undoubtedly, this paper does not attempt to discuss all aspects of water isotopes modeling in a single review. It focuses on global isotopic studies for present-day climate, that is, the past fifty years or so. It does not cover much on regional studies and paleoclimatology although these areas are equally important in atmospheric science. For regional and paleoclimatic studies, readers could refer to studies by Yao et al. [4] and Sturm et al. [2]. While much effort is made to ensure a comprehensive review on the focus area, some studies might have been overlooked unintentionally.

This paper aims to cater to a wide audience, including nonspecialists who might not be familiar with the concepts and terminologies in isotope hydrology. Section 2 covers the main concepts in water isotope fractionations in the atmosphere. Section 3 provides an overview of AGCMs that have incorporated water isotopes. Section 4 synthesizes recent advances in water isotopes modeling. Section 5 discusses future prospects of modeling and model validation. In the 
end, Section 6 concludes this review paper. Specialists could comfortably skip Section 2 and head directly to later sections.

\section{Water Isotopes in the Atmosphere}

Earth's hydrological cycle consists of key processes such as evaporation, condensation, and precipitation. Figure 1 is a schematic illustration of these processes. When water evaporates from the ocean surface, it becomes depleted in deuterium (D) and ${ }^{18} \mathrm{O}$ because $\mathrm{H}_{2}^{16} \mathrm{O}$, being isotopically lighter, evaporates slightly more easily than the heavier isotopologues. Water vapor cools during ascent and gets transported to continents by atmospheric dynamics. When the ambient temperature reaches the dew point, it condenses and forms rain droplets. Heavy isotopologues are preferentially removed from the rain. This results in more depletion of ${ }^{18} \mathrm{O}$ and $\mathrm{D}$ in the residual air mass.

Precipitation exhibits a few isotopic fractionation effects that have been discovered and studied. For example, going further into the continental areas, the air masses become even more depleted in heavy isotopes. This is commonly known as the "continental effect." Another effect is the "latitude effect." Figure 2 shows a schematic representation of atmosphere water vapor getting more depleted in ${ }^{18} \mathrm{O}$ as it moves to higher latitudes. When it reaches the poles, it has been significantly depleted in both ${ }^{18} \mathrm{O}$ and $\mathrm{D}$. In addition, it has been observed that the depletion of heavy isotopes is related to the intensity of the rain, especially in the tropical regions with frequent intense rainfalls [5]. Figure 3 shows a time series of rainfall and $\delta^{18} \mathrm{O}$ over two days. During the fall of raindrops, small raindrops fall slowly and equilibrate with ambient vapor quickly [3]. Conversely, during heavy rains, the large raindrops are less equilibrated with the ambient vapor because their transit time through the atmosphere is shorter compared to that of a small raindrop. As the rainfall gets more intense, it also gets more depleted in ${ }^{18} \mathrm{O}$. This intriguing "amount effect" has been an active area of research.

In phase transitions, hydrogen isotopes are fractionated in proportion to oxygen isotopes, because there is a corresponding difference in vapor pressures between the $\mathrm{H}_{2} \mathrm{O}$ HDO pair and the $\mathrm{H}_{2}^{16} \mathrm{O}-\mathrm{H}_{2}^{18} \mathrm{O}$ pair [6]. Craig first defined this relationship as follows: $\delta D=8 \delta^{18} \mathrm{O}+10$, where $\delta=$ $\left[\left(R_{\text {sample }} / R_{\text {standard }}\right)-1\right] \times 1000, R_{\text {standard }}$ being the Vienna Standard Mean Ocean Water (VSMOW) isotopic ratio [7, 8]. This straight line, known as the "Meteoric Water Line" (MWL), is shown in Figure 4. For example, at high altitude or continental inlands, the air mass is heavily depleted in $\mathrm{D}$ and ${ }^{18} \mathrm{O}$, making it sit at the lower left-hand corner of the graph. Dansgaard [5] introduced a concept of "deuterium excess," defined as $d=\delta D-8 \delta^{18} \mathrm{O}$. It could be seen as an index of deviation from the MWL. Deuterium excess (Dexcess) is a useful parameter because it is correlated with the physical conditions (humidity, air temperature, and sea surface temperature (SST)) of the vapor source regions [9]. For more details on isotopes in the atmosphere, readers could refer to Hoefs [6], Dansgaard [5], and Gat [10].

It has been recognized that water isotopes are independent quantities depending on many climate factors, such as vapor source conditions, circulation, local precipitation, and ambient temperature [1]. In order to account for all these climate factors in a holistic analytic framework, researchers have put much effort to incorporate water isotopes into AGCMs. Section 3 briefly introduces these models and Section 4 reviews and synthesizes recent advances in modeling and validation.

\section{Water Isotopes in AGCMs}

Since the first AGCM was developed by Norman Philips in 1956, GCMs have served as virtual laboratories for climate studies. The Laboratoire de Météorologie Dynamique model is the first model in which the physics of water isotopes is successfully incorporated into an AGCM [11]. In the past three decades, almost a dozen isotope-enabled AGCMs have been developed around the world. Figure 5 shows an overview of the isotope fractionation processes built into an AGCM. All phase transitions such as evaporation, condensation, precipitation, and water vapor transport have been numerically accounted for through parameterization schemes. For example, the Craig-Gordon model is commonly used for parameterization of evaporation from both open water and through vegetation $[12,13]$.

Inside an AGCM the globe is divided into hundreds of parameterized air columns. Figure 6 shows a single-column model by Risi [14]. The parameterizations include a radiation scheme, a cloud scheme, a convection scheme, and others. With large-scale dynamics air masses are transported from one column to another, and their isotopic signatures are updated. Putting all air columns together the AGCMs offer global simulation of water isotopes. In order to gain an overview of the main AGCMs published in the literature, a list of global AGCMs has been compiled in Table 1. Discussions in later sections will refer to the model acronyms frequently.

A review paper by Hoffmann et al. [1] provides an overview of AGCM simulations. The authors compared model outputs from GISS and ECHAM and also compared them with ground-based measurements from GNIP (Global Network of Isotopes in Precipitation). They attributed model deficiencies to transport schemes and simulated climate in the models. In addition, Jouzel et al. [15] examined progress made in isotope modeling in the 1990s. The next section offers a review on the recent advances in modeling and validation.

\section{Recent Advances in Modeling and Validation}

Since 2000, the modeling community has made tremendous progress in modeling the dynamical and physical mechanisms in isotope hydrology. This section aims to review the recent advances in water isotopes modeling and validation. To facilitate interdisciplinary dialogues and to avoid being unnecessarily bogged down by too much technical detail, discussions are carried out with minimal mathematical arguments. For more rigorous mathematical treatments on modeling evaporation, cloud processes, and postcondensation processes, readers could refer to a comprehensive 


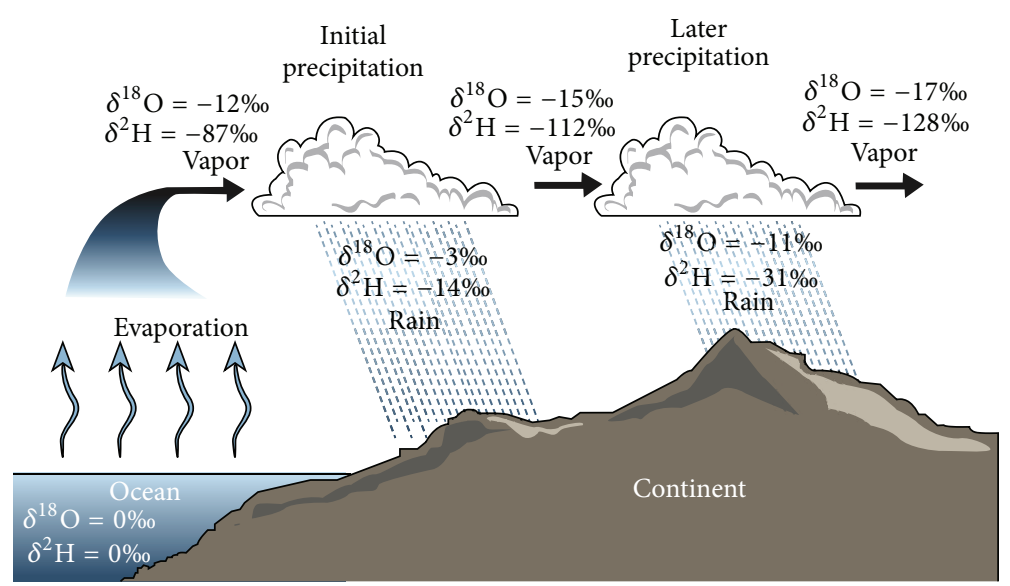

Figure 1: $\delta^{2} \mathrm{H}($ or $\delta \mathrm{D})$ and $\delta^{18} \mathrm{O}$ as imprints of hydrological processes. Based on Hoefs [6] and Coplen et al. [51]. This figure is adapted from SAHRA [52].

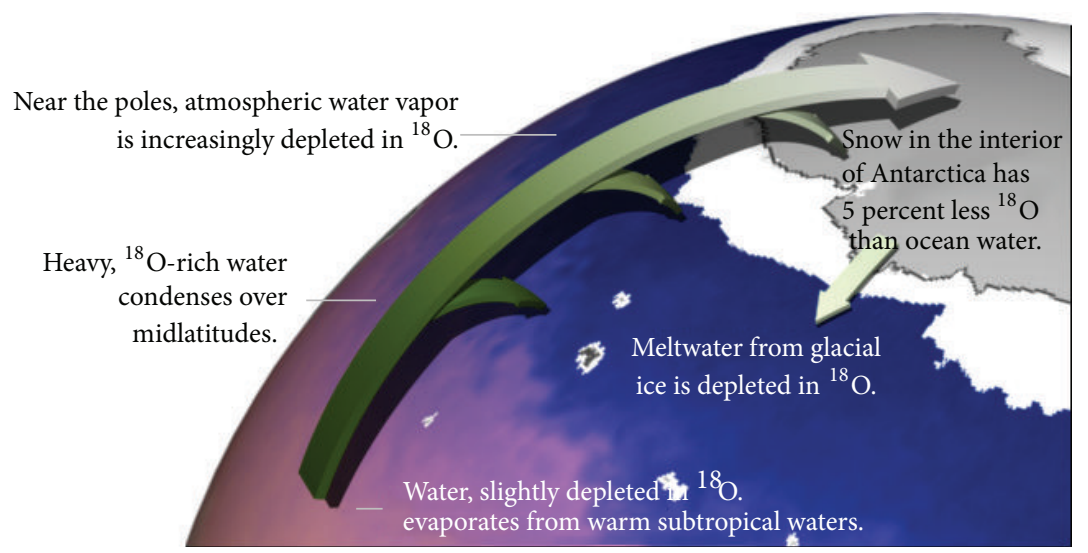

FIGURE 2: Schematic representation of the "latitude effect" on water isotope fractionation. This figure is adapted from Earth Observatory [53].

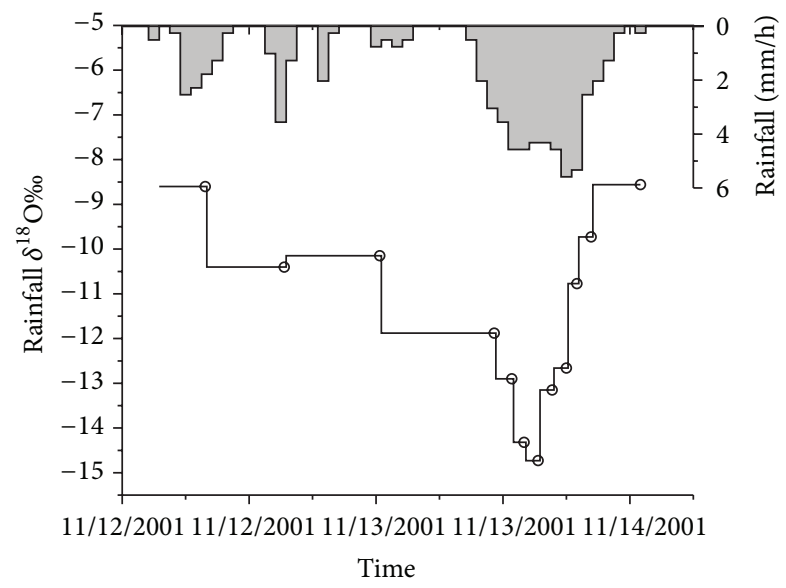

Figure 3: Observed "amount effect." This figure is adapted from McGuire and McDonnell [54].

introduction by Noone and Sturm [3]. Instead, this section focuses more on the key advances in model development and validation from 2000 to May 2014. The omission of studies published earlier than this time period is due to the fact that

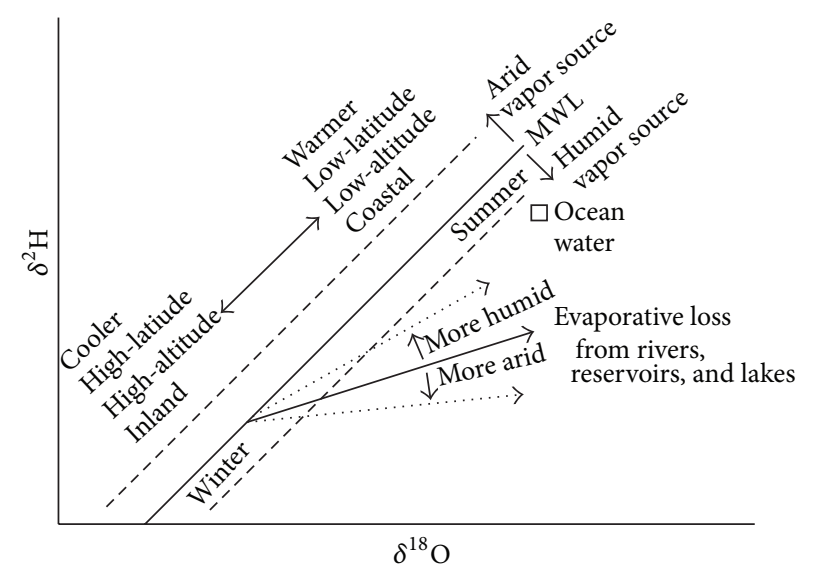

FIgURE 4: Meteoric water line (MWL). This figure is adapted from SAHRA [52].

papers by Jouzel et al. [15] and Hoffmann et al. [1] on that particular topic have already discussed model developments from the 1960s to 1990s. 


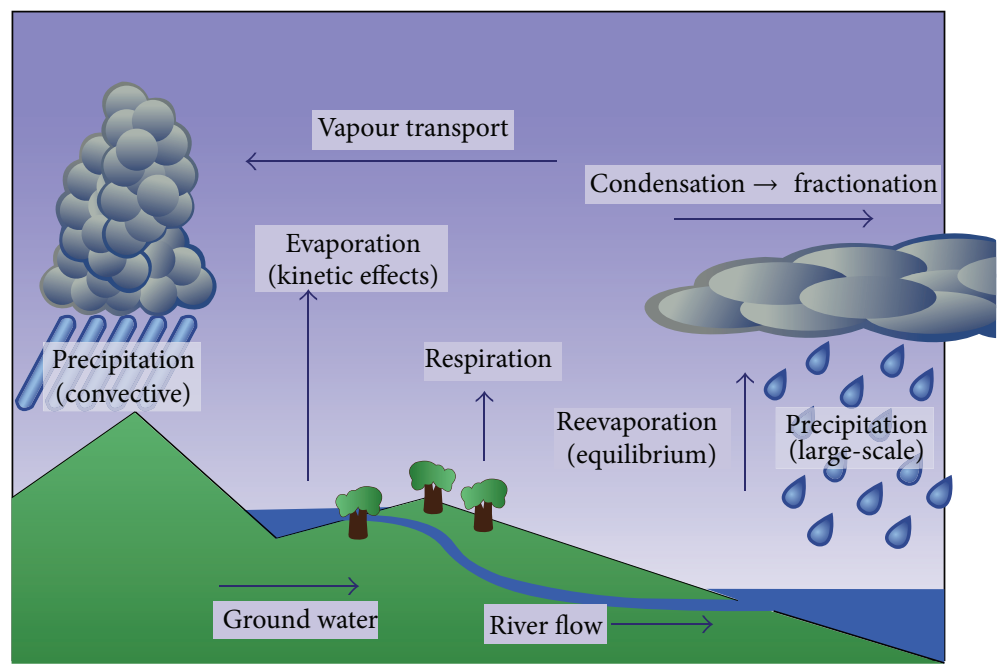

FIGURE 5: Schematic representation of the global hydrological cycle and the fractionation processes built into the ECHAM model. This figure is originally from Hoffmann et al. [1] and is modified by Herold [55]. "Transpiration" is a more appropriate term for the evaporation of water from plants to the atmosphere.

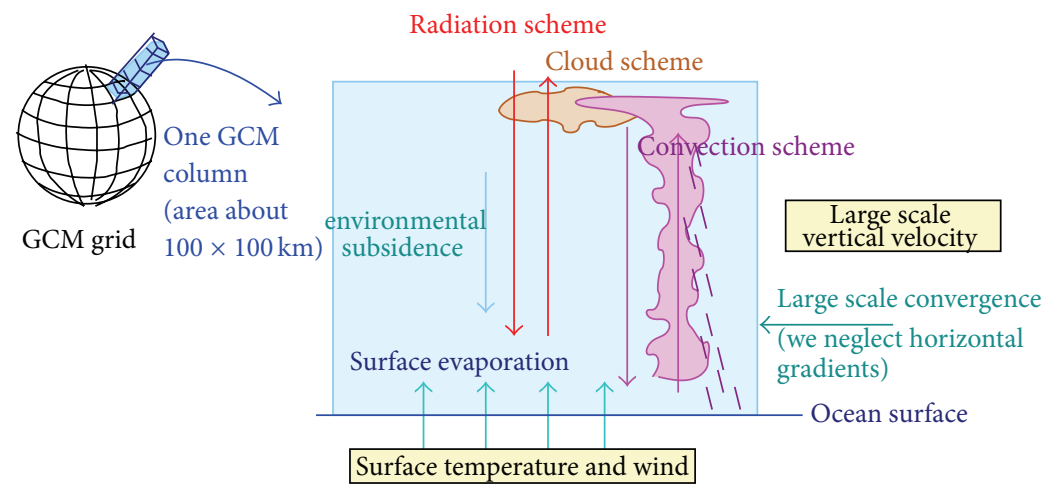

FIGURE 6: Single-column model that consists of a radiation scheme, a cloud scheme, a convection scheme, and other parameterizations. This figure is adapted from Risi [14].

\subsection{Advances in Model Development}

4.1.1. Surface Evaporation. In many models, evaporation from the ocean surface is based on the full theory of surface water-atmosphere isotopic exchange developed by Merlivat and Jouzel in 1979 [16]. This theory includes both equilibrium and kinetic fractionations. However, kinetic isotopic fractionation lacks experimental foundations. Through controlled experiments, Cappa et al. [17] argued that surface cooling of the liquid, a variable that was not properly incorporated in modeling before, is a crucial component affecting isotopic fractionation from evaporating water. They provided new isotopic molecular diffusivity ratios through experimental work and advocated that incorporating these realistic ratios and surface cooling due to evaporation would have a significant impact on the isotopic composition of precipitation, especially at high latitudes. Since then, Tindall et al. [18] have adopted the new diffusivity ratios in HadCM3. However, they did not elaborate much on the improvements made due to the use of new diffusivity ratios.
Over land, many AGCMs use a "bucket" scheme to simulate evaporation from the land surface. In this scheme, precipitation minus evaporation minus runoff fills a shallow top layer and any overflow fills a lower bottom reservoir [19]. The major limitation of this scheme is its simplicity and its inability to simulate dynamic surface hydrology. As a result, any isotope fractionation during surface evapotranspiration processes has been neglected. To overcome this limitation, a few more sophisticated land surface schemes [19-21] have been developed. For example, Haese et al. [19] developed a coupled atmosphere-land surface model named ECHAM5JSBACH. Comparisons between the coupled and the original models reveal the impact of coupling on the simulated temperature and soil wetness. The $\delta^{18} \mathrm{O}$ in precipitation in coupled model differs from the original one by about $4 \%$.

4.1.2. Condensation. The formation of ice or liquid condensate from clouds is usually implemented as a Rayleigh distillation in an open system. This is often regarded as "firstgeneration" isotope scheme for cloud processes [3]. Although 


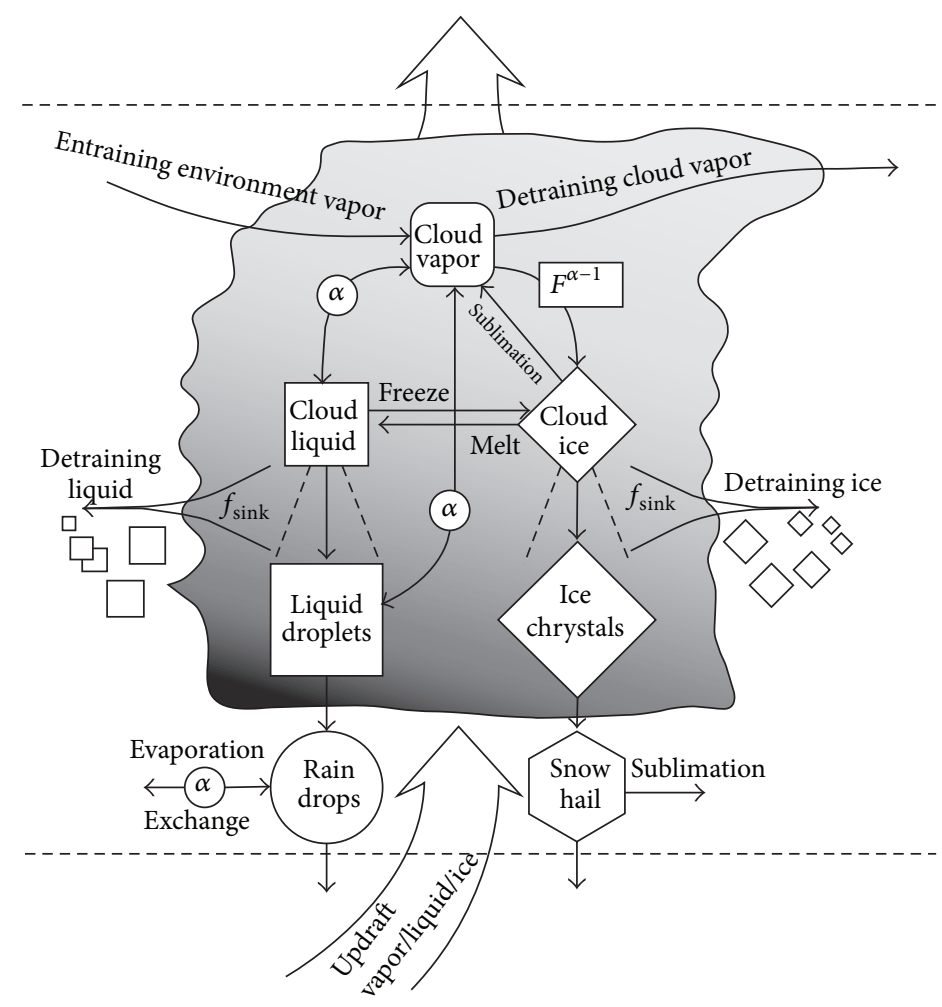

FIGURE 7: Schematic depiction of the third-generation isotope scheme describing the cloud microphysics for isotopes used in CAM3. It includes detailed exchanges between in-cloud properties and the environment and accounts for multiple microphysical moments and transport processes. The letter $\alpha$ stands for the fractionation factor during a phase transition and $F^{\alpha-1}$ is equal to $R / R_{o}$, where $R$ and $R_{o}$ are the current and initial isotope ratios in the cloud vapor, respectively. This figure is adapted from Noone and Sturm [3].

this condensation scheme based on Rayleigh distillation provides satisfying results in many applications [3], it does not take into account the physics inside clouds and could not improve our understanding of the large-scale geographic distribution of water isotopes in precipitation [22]. A secondgeneration cloud isotope scheme incorporates more physics in clouds. For example, many AGCMs simulate convective updrafts and downdrafts as pathways for water vapor transport [3]. A third-generation scheme could simulate complex cloud microphysical processes. Figure 7 illustrates the multiple exchanges between in-cloud properties and the environment, microphysical processes, and transport processes. The downside is that the isotopic microphysics needs to be solved via numerical integration, which is computationally demanding [3].

4.1.3. Supersaturation. The Rayleigh model assuming isotopic equilibrium could not explain the amount of deuterium and ${ }^{18} \mathrm{O}$ in polar snow. Jouzel and Merlivat [23] presented a model that accounts for the existence of an isotopic kinetic effect at snow formation. They suggested an empirical relation between supersaturation $\mathrm{Si}$ and condensation temperature $T$ $\left({ }^{\circ} \mathrm{C}\right)$ as $\mathrm{Si}=0.99-0.006 \times T$. Many AGCMs use a similar approach for parameterizing supersaturation. For instance, MUGCM uses a slightly modified relation, $\mathrm{Si}=1-0.003 \times T$. The parameter before $T$, a tunable parameter, is often referred to as $\lambda$. After running a series of sensitivity tests, Risi et al. [24] found that $\lambda$ in the parameterization of the supersaturation during snow formation affects the precipitation composition substantially. Figure 8 shows the fitting of model outputs to measurements made in Antarctica. Through comparison, it is clear that $\lambda=0.004$ fits the data much better. Werner et al. [25] reported better fitting with measurements after setting $\mathrm{Si}=1.01-0.0045 \times T$. This empirical and heuristic tuning of parameters does lead to better agreement between model outputs and observations. Better understanding of the snow-formation processes are needed but are hampered by the lack of appropriate measurements such as the degree of supersaturation in clouds [26].

4.1.4. Postcondensation Processes. As discussed in Section 2, precipitation exhibits an intriguing amount effect: as the rainfall gets more intense, it also gets more depleted in ${ }^{18} \mathrm{O}$. Although scientists have come up with some hypotheses to explain the amount effect, few quantitative studies are done. In an attempt to fill this knowledge gap, Lee and Fung [27] proposed a numerical model that describes the interactions of raindrops and water vapor near the planetary boundary layer. Figure 9 shows $\delta^{18} \mathrm{O}$ as a function of drop radius at different levels of relative humidity $(\mathrm{RH})$. Larger raindrops are more depleted in ${ }^{18} \mathrm{O}$. At lower $\mathrm{RH}$, small raindrops evaporate quickly. Some of them (radius $<0.6 \mathrm{~mm}$ ) reevaporate and do not reach the boundary layer at $\mathrm{RH}=70 \%$. The authors 


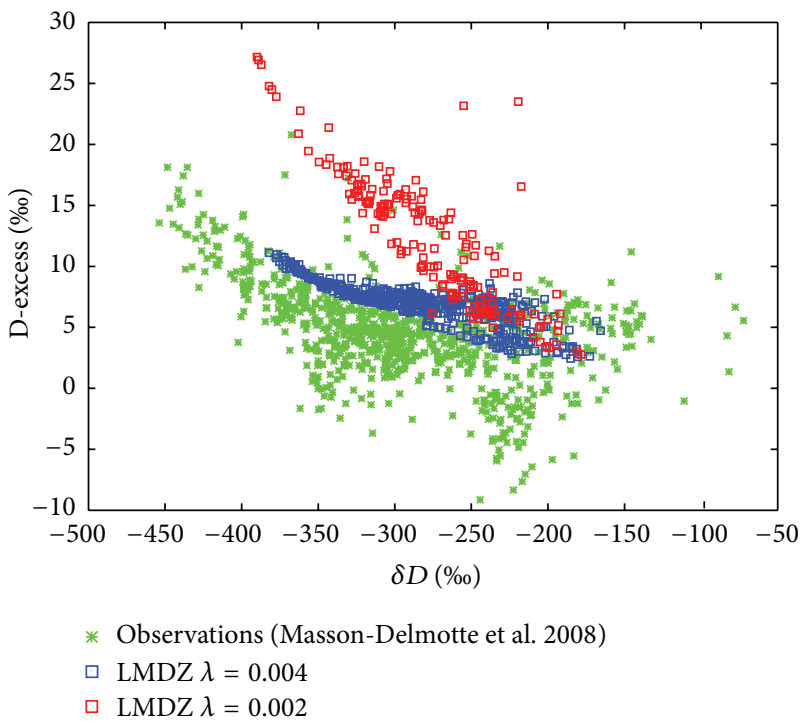

Figure 8: Annual mean D-excess as a function of annual mean $\delta \mathrm{D}$ in precipitation in Antarctica, in the data from Masson-Delmotte et al. [56] (green) and in LMDZ-iso free simulations (blue and red). In blue, the supersaturation $\lambda$ is set to its typical value of 0.004 , whereas in red it is set to 0.002. This figure is adapted from Risi et al. [24].

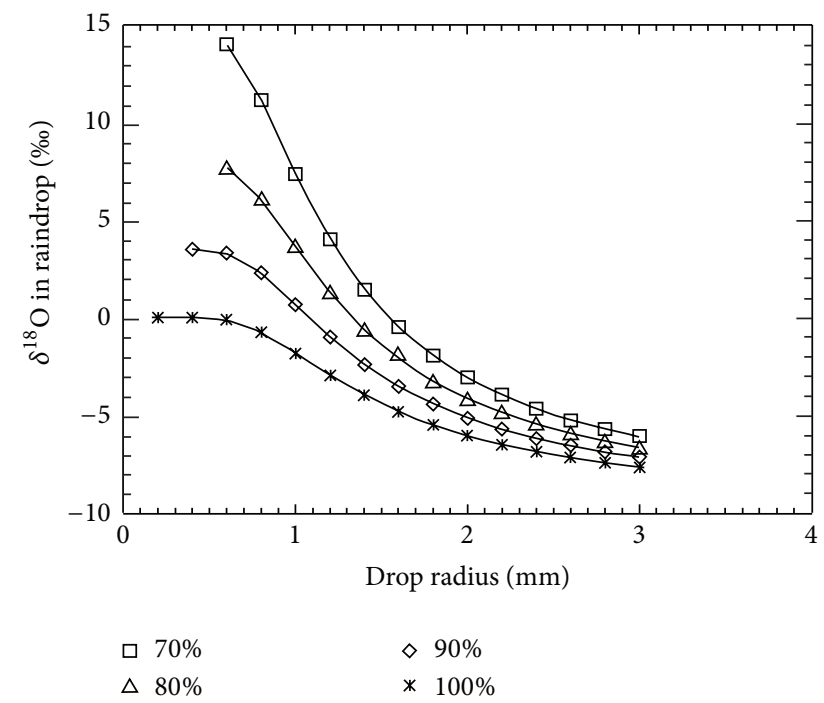

FIgURE 9: $\delta^{18} \mathrm{O}$ as a function of drop radius. This figure is adapted from Lee and Fung [27].

further emphasized that the amount effect is sensitive to both temperature and precipitation rate. The simulated $\delta^{18} \mathrm{O}$ matches observations well. This model could be applied to AGCMs to improve the simulation of the amount effect.

In general, parameterization of postcondensation processes vary significantly among AGCMs. For example, Figure 10 shows that, in LMDZ4, the parameterized physical processes include convective updrafts, unsaturated downdrafts, and vapor recycling. In GENESIS, downdrafts are not simulated explicitly, and environmental effects on isotopic processes are approximated from in-cloud conditions [26].
This difference in parameterization is perhaps one cause of the differences among various model outputs.

4.1.5. Vertical Distribution of Water Isotopes. Water isotopes in the upper troposphere and stratosphere are poorly constrained in AGCMs, partly due to poor simulations of the middle atmosphere and sparse measurements. Schmidt et al. [28] examined stratosphere-troposphere water exchange with GISS ModelE. This model includes improvements in cloud physics and a source of water associated with methane oxidation. Figure 11 shows the tropical near-tropopause water vapor in July. It demonstrates that the mixing processes simulated by the model can explain a substantial part of the observed sub-Rayleigh behavior. Here, mixing processes refer to the mixing of two or more air parcels with distinct isotope ratios. For example, air parcels originated from the troposphere could mix with those in the stratosphere during convection. Yoshimura et al. [29] corroborated that in lowertroposphere, a Rayleigh-type rainout effect dominates. In the mid-troposphere, it is more affected by the mixing processes.

In addition, Wright et al. [30] examined the direct effect of condensate evaporation on the vertical distribution of atmospheric water vapor and its isotopic composition through a simulation experiment with GISS ModelE. They ran two model simulations, one with passive cloud and precipitation evaporation and one without (control case). The results show that disabling condensate evaporation dries the modeled atmosphere by about $5 \%$ to $25 \%$, depending on the location. Zonal mean water vapor is enriched in $\mathrm{HDO}$ in the lower and middle troposphere and depleted in the upper troposphere, relative to the control case without condensate evaporation. Their findings highlight the impact of condensate evaporation on the vertical profile of water isotopes.

4.1.6. Spatial $\delta^{18} O$-Temperature Slope. The $\delta^{18} \mathrm{O}$ record from ice cores has been traditionally used as a proxy for temperature variations over time. Through examining the spatial $\delta^{18} \mathrm{O}$-temperature relation, researchers have found that there are complications associated with the $\delta^{18} \mathrm{O}$ record. Noone and Simmonds [13] conducted a simulation of atmospheric circulation from 1979 to 1995 and examined the association between the modeled isotopic signal, temperature, and precipitation. Figure 12 shows the partial correlation of $\delta^{18} \mathrm{O}$ values and temperature. Typically, only $20 \sim 50 \%$ of $\delta^{18} \mathrm{O}$ variance could be explained by temperature changes. This study for present-day climate implies that accurate interpretation of proxy records in paleoclimate studies require significant knowledge of the physical and chemical processes through which the record was created. Schmidt et al. [31] corroborated this finding and argued that a more robust way to reconstruct past climate is to examine the spatial and nonlocal evolutions of isotope signals.

4.1.7. Spectral Nudging Technique. In recent years, a spectral nudging technique with reanalysis datasets (e.g., horizontal winds from NCEP reanalysis) has been applied to some AGCMs to constrain large-scale atmospheric circulations. As 


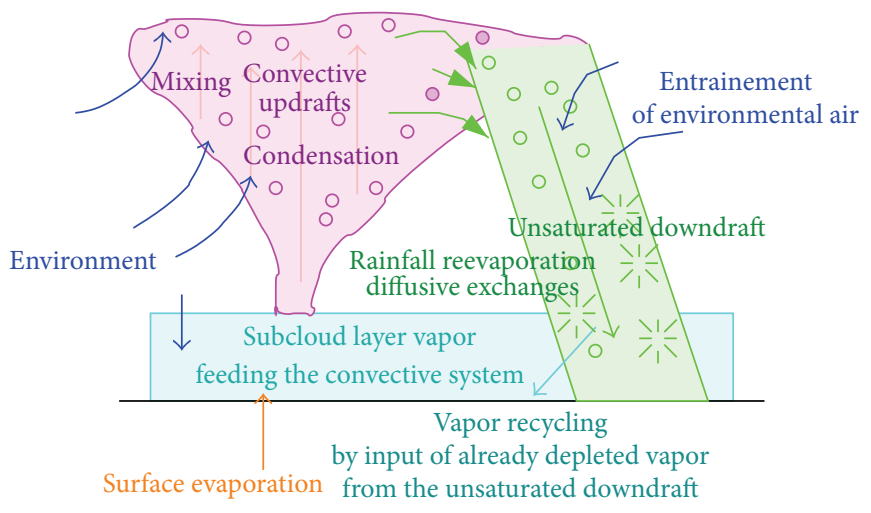

FIGURE 10: Schematic illustration of how the amount effect is decomposed into a sum of different contributions, each corresponding to a single or to an ensemble of physical processes. This figure is adapted from Risi [14].

a result, the dynamic fields are close to observations and the simulated isotopic fields are also more accurate compared to observations from synoptic to interannual time scales $[13,24$, 32, 33]. For example, Risi et al. [24] reported that nudging the model winds by ERA-40 reanalyses improves the simulation of temperature and $\delta^{18} \mathrm{O}$ at middle latitudes.

4.1.8. Higher Model Resolutions. Moving towards higher model resolutions is a general trend in the modeling community, in atmospheric science and beyond. In isotopes modeling, the need for higher resolutions is quite relevant. Both Mathieu et al. [26] and Noone and Simmonds [13] noted that the current model resolution is not fine enough to fully capture the dynamical effects over steep topography, so most of the model temperature and isotopic errors are located in mountainous areas. Yao et al. [4] corroborated that the models have caveats for the representation of climate relationships in the Tibetan Plateau. Mathieu et al. [26] and Sturm et al. [2] also pointed out that models with coarse resolutions could not fully resolve cloud processes and convection. Sturm et al. [2] reasoned that many processes could not be resolved explicitly in the dynamical core, because they take place at much smaller scales. For example, convective cloud systems develop over an area of a few kilometers, two orders of magnitude smaller than one grid cell. Higher resolutions would help to resolve finer physics within a grid cell and facilitate more meaningful collocation comparisons with a single point value from ground-based measurements.

Werner et al. [25] explored the gain from higher model resolutions with ECHAM5-wiso. They ran simulations with model resolutions that vary from a coarse horizontal grid of $3.8^{\circ} \times 3.8^{\circ}(\mathrm{T} 31)$ to a fine grid of $0.75^{\circ} \times 0.75^{\circ}(\mathrm{T} 159)$. Vertical resolution varies from 19 to 31 levels. Figure 13 shows the simulation results, as compared to GNIP ground-based measurements. It is found that the simulations with the fine model resolution resolve some of the features over the ocean and result in a better agreement with GNIP datasets. They attributed this improvement to better realization of largescale moisture transport.

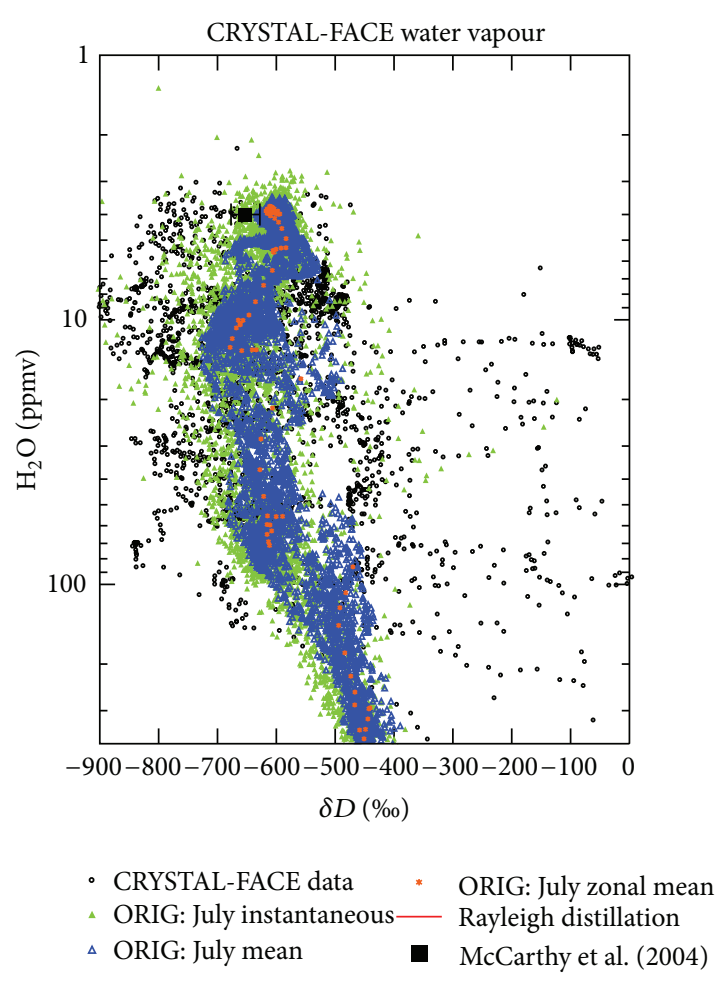

FIGURE 11: July tropical near-tropopause water vapor. The observations from CRYSTAL-FACE campaign deviate from Rayleigh distillation model. The model that includes mixing processes could explain a substantial part of the sub-Rayleigh behavior. ORIG refers to outputs from original simulation. The data from McCarthy et al. [57] (black square). This figure is adapted from Schmidt et al. [28].

4.1.9. Coupled Atmosphere-Ocean Models. Some GCMs are coupled atmosphere-ocean models that trace water isotopes in both atmospheric and oceanic subsystems. These coupled models have been used to study climate phenomena that involve strong air-sea interactions. For example, HadCM3 contains an atmospheric component (HadAM3) and oceanic component (HadOM3). It was used by Tindall et al. [18] 


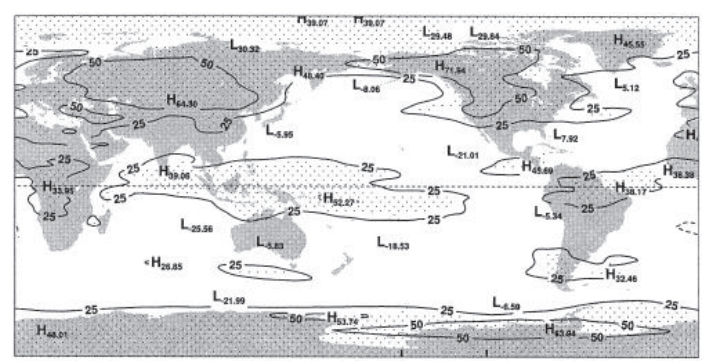

FIgURE 12: Partial correlation $(\times 100)$ of $\delta^{18} \mathrm{O}$ values and temperature. Negative contours are dashed and the zero contour is omitted. Stippling indicates where the magnitude of the correlation exceeds 25 and is significant at $\alpha=0.05$. This figure is adapted from Noone and Simmonds [13].

to study the isotopic signature of ENSO (El Niño-Southern Oscillation) and tropical amount effect. Figure 14 shows the difference in model outputs between El Niño composite and the long-term mean climate. The characteristics of El Niño, such as warm surface temperature and high precipitation anomalies in the central Pacific, are captured well by the coupled model. The pattern of $\delta^{18} \mathrm{O}_{p}$ values matches the precipitation pattern, with some spatial shifts due to the effects of the upstream rainout on $\delta^{18} \mathrm{O}_{p}[18]$.

4.2. Advances in Model Validation. As Patrick Crill put it, "data without models are chaos, but models without data are fantasy" [34]. The importance of model validation could not be overemphasized. This section reviews a suite of groundbased and spaceborne measurements of water isotopes and synthesizes the model-data comparisons and new insights derived. In order to have a comprehensive overview, a list of datasets is compiled in Table 2. It includes full names and acronyms of the datasets. For brevity, only the acronyms of the datasets are mentioned in this section.

4.2.1. Ground-Based Measurements. Since 1961, the International Atomic Energy Agency's (IAEA) water resources programme and the World Meteorological Organization (WMO) have been measuring the stable hydrogen and oxygen isotope and tritium composition in precipitation worldwide [35]. Some of the stated objectives of GNIP are (1) to verify and improve GCMs and (2) to deduce atmospheric circulation patterns and movement of water [5]. More information about GNIP datasets could be found in a review paper by Rozanski et al. [36]. Besides GNIP, TCCON measures column-averaged $\mathrm{H}_{2} \mathrm{O}$ and $\mathrm{HDO}$ using high-resolution Fourier transform spectrometers (FTS). More details about TCCON datasets are presented in Wunch et al. [37]. NDACC uses ground-based Fourier transform infrared spectrometers to measure tropospheric $\mathrm{H}_{2}^{16} \mathrm{O}$ and $\mathrm{HD}^{16} \mathrm{O} / \mathrm{H}_{2}^{16} \mathrm{O}$ [38]. In general, ground-based measurements of water isotopes are of high precision and are used as benchmarks to calibrate spaceborne measurements.

4.2.2. Spaceborne Measurements. Even though groundbased measurements are of high quality, the network of FTS instruments could hardly provide global coverage needed for model validation. The modeling community has dreamt of direct evaluation of isotopes in water vapor on a global scale [3]. In the satellite era, spaceborne measurements of $\delta \mathrm{D}$ from ACE, GOSAT, IASI, IMG, MIPAS, SCIAMACHY, and TES have significantly improved our understanding of the global distribution of water isotopes in the atmosphere. These measurements are made possible because the spectroscopic signatures of $\mathrm{H}_{2} \mathrm{O}$ and $\mathrm{HDO}$ are distinguishable from each other, so the relative abundance of the two species can be retrieved from the radiances measured from space. Expectedly, the precision of spaceborne measurements is almost one order of magnitude worse than the ground-based counterparts. Table 2 contains the estimated precision for each dataset.

4.2.3. Model Validation with Measurements. Comparisons between ground-based measurements and model outputs are accomplished through collocating model outputs with the data on daily time scale [33]. Figure 13 shows the comparison between the GNIP dataset and output from ECHAM5-wiso. The differences between model and data are in the range of $\pm 10 \%$ o for near-surface atmospheric values at a few GNIP stations [25]. The collocation method is not perfect because it ignores spatial variations at small scales that could result in differences between $\delta \mathrm{D}$ from a small footprint instrument and $\delta \mathrm{D}$ in a relatively larger AGCM grid cell [33]. For more details about model-data comparison methodology, readers could refer to Risi et al. [33].

One of the first global maps of $\delta \mathrm{D}$ is based on SCIAMACHY's spaceborne measurements [39]. In the same paper, the authors made a comparison between modeled latitudinal isotope gradients and SCIAMACHY observations. Their results suggest that IsoGSM underestimates the latitudinal gradient: AGCMs tend to underestimate the tropical $\delta \mathrm{D}$ values and overestimate subtropical $\delta \mathrm{D}$ values. In a followup paper, Yoshimura et al. [29] discovered model-data discrepancies over Tibet Plateau and Maritime Continents that are likely derived from the poor parameterization of isotopic behavior in convection and postcondensation processes.

Although spaceborne measurements of $\delta \mathrm{D}$ could serve as process-oriented benchmark for AGCMs, they are also subject to inaccuracies in instrument calibrations and water vapor spectroscopy. Yoshimura et al. [29] used a $\delta \mathrm{D}$ offset of $-20 \%$ in SCIAMACHY and $20 \%$ in TES. These offsets are thought to be due to systematic errors at higher latitudes in satellite products or of unknown origins [25, 39, 40]. Figure 15 shows that, with improved instrument calibration and water vapor spectroscopy, the updated $\delta \mathrm{D}$ value is different from original $\delta \mathrm{D}$ by as much as $80 \%$ [41]. Thus, spaceborne measurements have their known shortcomings and could not be regarded as absolute truth or perfect benchmark for AGCMs.

The general purpose of the SWING (Stable Water Isotope Intercomparison Group) initiative is to have an international comparison among the current state-of-the-art isotopeenabled AGCMs and related isotope measurements [42]. It brings together researchers from both the modeling and 


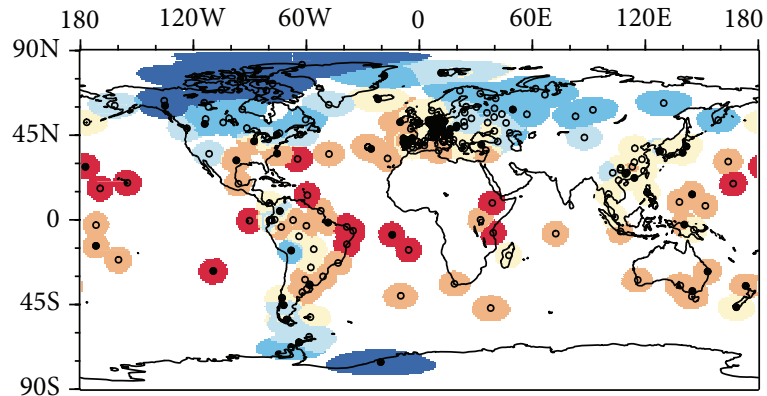

(a) GNIP

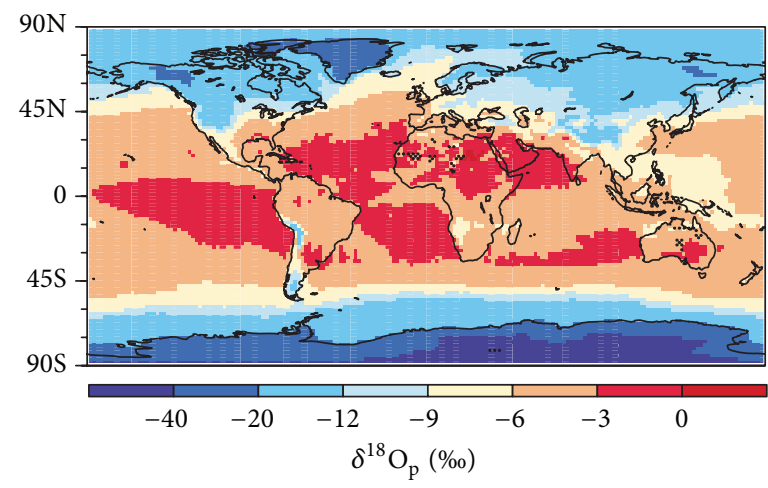

(c) T63L31

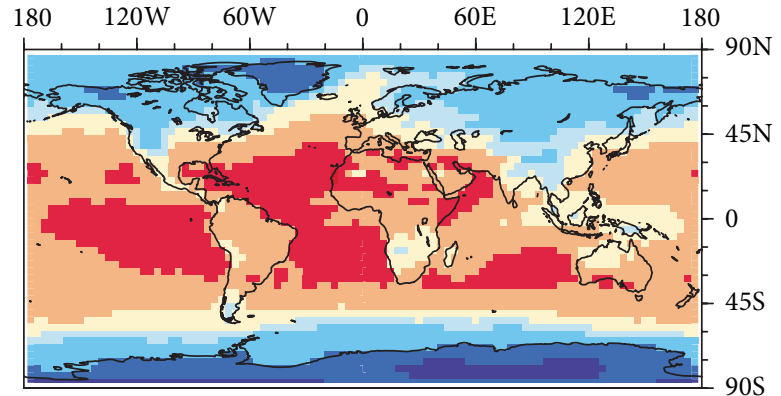

(b) T31L19

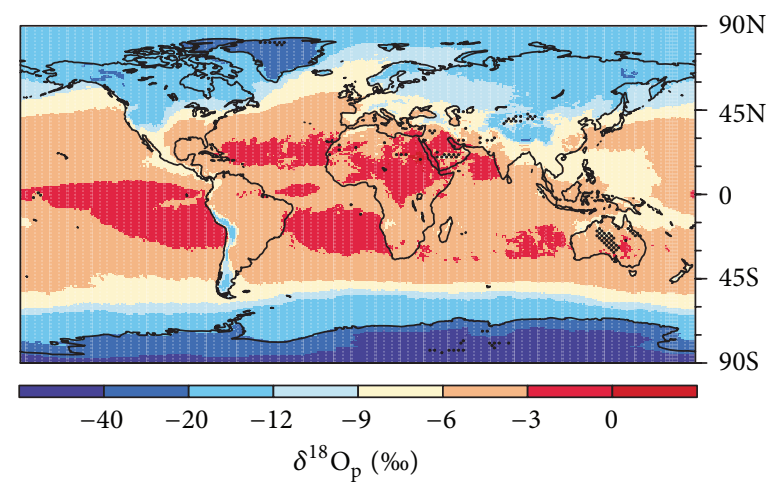

(d) T159L31

FIGURE 13: Global maps of observed and simulated present-day mean annual $\delta^{18} \mathrm{O}_{p}$ based on GNIP datasets. Figures (b) to (d) show results of three ECHAM5-wiso simulations with different horizontal and vertical model simulations. In each of these plots, the simulated mean $\delta^{18} \mathrm{O}_{p}$ values are plotted on the raw model grid without additional interpolation. The hatched areas mark those model grid cells where the simulated year-to-year variability of $\delta^{18} \mathrm{O}_{p}$ is larger than $\pm 2 \%$. This figure is adapted from Werner et al. [25].

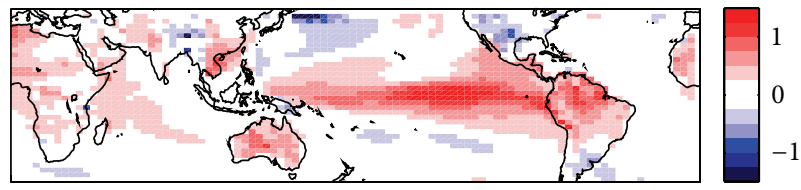

(a) Surface temperature $(\operatorname{deg} \mathrm{C})$

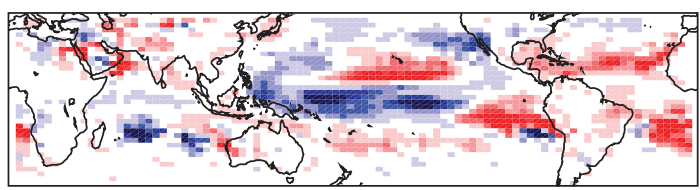

(c) $\delta^{18} \mathrm{O}_{p}($ per mille)

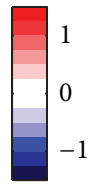

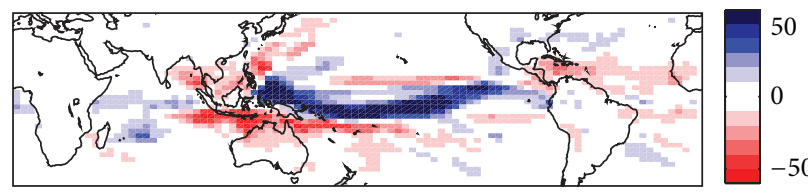

(b) Precipitation ( $\mathrm{mm} / \mathrm{month})$

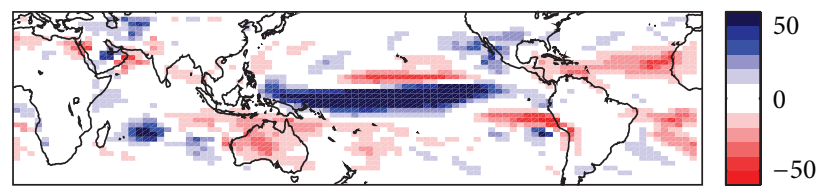

(d) Precipitation (percentage change)

FIgURE 14: HadCM3L difference between El Niño composite and the long-term mean climate. This figure is adapted from Tindall et al. [18].

measurement community. The first phase of SWING simulations and analyses focus on model-data comparisons for the present-day climate. Three AGCMs, namely, ECHAM4, GissE, and MUGCM, are run for a 20-year simulation with identical boundary conditions. Figure 16 shows the comparison between model outputs and GNIP measurements. All models are able to simulate the main characteristics of the global pattern such as latitude effect and continental effect. However, model results show some discrepancies at regions such as South Africa, Tibet Plateau, and Greenland.
However, all three GCMs fail to simulate some processes influencing D-excess values. Also, they could not reproduce the strong positive D-excess values over the Mediterranean Sea [42]. Some causes of the discrepancies among model results are different internal structures, model resolutions, and advection schemes.

The second phase of SWING simulations and analyses include seven isotopic AGCMs and the main focus is also on present-day model-data intercomparison. Some are nudged by reanalyses while others are not. Risi et al. [33] 
TABLE 2: Global Ground-based and Space-borne Measurements* .

\begin{tabular}{|c|c|c|c|c|c|}
\hline Measurement & Main operator & Relevant datasets & Precision & Time period & References \\
\hline $\begin{array}{l}\text { GNIP } \\
\text { (Global Network of } \\
\text { Isotopes in } \\
\text { Precipitation) }\end{array}$ & IAEA/WMO & $\begin{array}{c}\delta \mathrm{D}, \delta^{18} \mathrm{O} \text {, and tritium } \\
\text { content }\end{array}$ & $\begin{array}{l} \pm 0.8 \% \text { for } \delta \mathrm{D} \text { and } \\
\pm 0.1 \% \text { for } \delta^{18} \mathrm{O}\end{array}$ & From 1961 onwards & $\begin{array}{c}\text { Dansgaard [5] } \\
\text { Rozanski et al. [36] }\end{array}$ \\
\hline $\begin{array}{l}\text { MUSICA } \\
\text { (MUlti-platform remote } \\
\text { Sensing of Isotopologues } \\
\text { for investigating the } \\
\text { Cycle of Atmospheric } \\
\text { water) }\end{array}$ & $\begin{array}{l}\text { The Institute for } \\
\text { Meteorology and } \\
\text { Climate Research } \\
\text { (IMK)-Atmospheric } \\
\text { Trace Gases and } \\
\text { Remote Sensing } \\
\text { (ASF) }\end{array}$ & Total-column $\delta \mathrm{D}$ & $10 \sim 25 \%$ o & $\begin{array}{l}\text { From } 1996 \\
\text { onwards }\end{array}$ & Schneider et al. [38] \\
\hline $\begin{array}{l}\text { NDACC } \\
\text { (Network for the } \\
\text { Detection of } \\
\text { Atmospheric } \\
\text { Composition Change) }\end{array}$ & $\begin{array}{c}\text { NOAA } \\
\text { (National Oceanic } \\
\text { and Atmospheric } \\
\text { Administration) }\end{array}$ & Total-column $\delta \mathrm{D}$ & $<10 \%$ & From 1991 onwards & Schneider et al. [38] \\
\hline $\begin{array}{l}\text { TCCON } \\
\text { (Total Carbon Column } \\
\text { Observing Network) }\end{array}$ & $\begin{array}{c}\text { Caltech } \\
\text { (California Institute } \\
\text { of Technology) }\end{array}$ & Total-column $\delta \mathrm{D}$ & $5 \sim 22 \%$ o & $\begin{array}{c}\text { From } 2004 \\
\text { onwards (varies } \\
\text { among stations) }\end{array}$ & Wunch et al. [37] \\
\hline $\begin{array}{l}\text { ACE } \\
\text { (Atmospheric Chemistry } \\
\text { Experiment) }\end{array}$ & $\begin{array}{c}\text { CSA } \\
\text { (Canadian Space } \\
\text { Agency) }\end{array}$ & $\delta \mathrm{D}$ & NA & $\begin{array}{l}\text { From } 2004 \\
\text { onwards }\end{array}$ & Bernath et al. [60] \\
\hline $\begin{array}{l}\text { GOSAT } \\
\text { (Greenhouse gases } \\
\text { Observing SATellite) }\end{array}$ & $\begin{array}{c}\text { JAXA } \\
\text { (Japan Aerospace } \\
\text { Exploration Agency) }\end{array}$ & Total-column $\delta \mathrm{D}$ & $20 \sim 40 \%$ & $\begin{array}{l}\text { June } 2009 \text { to } \\
\text { September } 2011\end{array}$ & Frankenberg et al. [61] \\
\hline $\begin{array}{l}\text { IASI } \\
\text { (Infrared Atmospheric } \\
\text { Sounding } \\
\text { Interferometer) }\end{array}$ & $\begin{array}{c}\text { CNES } \\
\text { (Centre National } \\
\text { d'Etudes Spatiales) }\end{array}$ & $\delta \mathrm{D}$ in troposphere & $\sim 37 \%$ & $\begin{array}{l}\text { From } 2007 \\
\text { onwards }\end{array}$ & Herbin et al. [62] \\
\hline $\begin{array}{l}\text { IMG } \\
\text { (Interferometric } \\
\text { Monitor for Greenhouse } \\
\text { gases) }\end{array}$ & $\begin{array}{c}\text { JAROS } \\
\text { (Japan Resources } \\
\text { Observation System } \\
\text { Organization) }\end{array}$ & Total-column $\delta \mathrm{D}$ & $20 \sim 170 \%$ о & 1996 to 1997 & Zakharov et al. [63] \\
\hline $\begin{array}{l}\text { MIPAS } \\
\text { (Michelson } \\
\text { Interferometer for } \\
\text { Passive Atmospheric } \\
\text { Sounding) }\end{array}$ & $\begin{array}{c}\text { ESA } \\
\text { (European Space } \\
\text { Agency) }\end{array}$ & $\delta \mathrm{D}$ in stratosphere & $36 \sim 111 \%$ & $\begin{array}{l}\text { June } 2002 \text { to March } \\
2004\end{array}$ & $\begin{array}{c}\text { Steinwagner et al. [64] } \\
\text { Payne et al. [65] }\end{array}$ \\
\hline $\begin{array}{l}\text { SCIAMACHY } \\
\text { (SCanning Imaging } \\
\text { Absorption } \\
\text { spectroMeter for } \\
\text { Atmospheric } \\
\text { CHartographY) }\end{array}$ & ESA & Column-averaged $\delta \mathrm{D}$ & $40 \sim 100 \%$ o & $\begin{array}{l}2003 \text { to } 2005 \\
\text { (more data is in } \\
\text { processing) }\end{array}$ & $\begin{array}{l}\text { Frankenberg et al. } \\
\text { [39] }\end{array}$ \\
\hline $\begin{array}{l}\text { TES } \\
\text { (Tropospheric Emission } \\
\text { Spectrometer) }\end{array}$ & $\begin{array}{c}\text { NASA } \\
\text { (National Aeronautics } \\
\text { and Space } \\
\text { Administration) }\end{array}$ & Total-column $\delta \mathrm{D}$ & $\sim 10 \%$ & $\begin{array}{l}\text { From } 2004 \\
\text { onwards }\end{array}$ & $\begin{array}{l}\text { Worden et al. [40] } \\
\text { Worden et al. [66] }\end{array}$ \\
\hline
\end{tabular}

${ }^{*}$ Air-borne measurements from aircrafts and balloon platforms are omitted here because they are more regional in nature. Ground-based measurements and spaceborne measurements are listed in alphabetical order in their respective subgroups. NA stands for not available.

conducted a comprehensive comparison between models and observations. They found that, although LMDZ reproduces the spatial patterns in the lower and mid-troposphere well, it underestimates the amplitude of seasonal variations in water isotopes in the subtropics and midlatitudes. This bias is consistent across all datasets and is common to all models participating in SWING. Investigating further, Risi et al. [43] examined the causes of a persistently moist bias in the tropical and subtropical mid-troposphere and upper troposphere that are simulated in AGCMs. They found that the moist bias is probably due to excessive diffusion during vertical water vapor transport. This study highlights the usefulness of water 


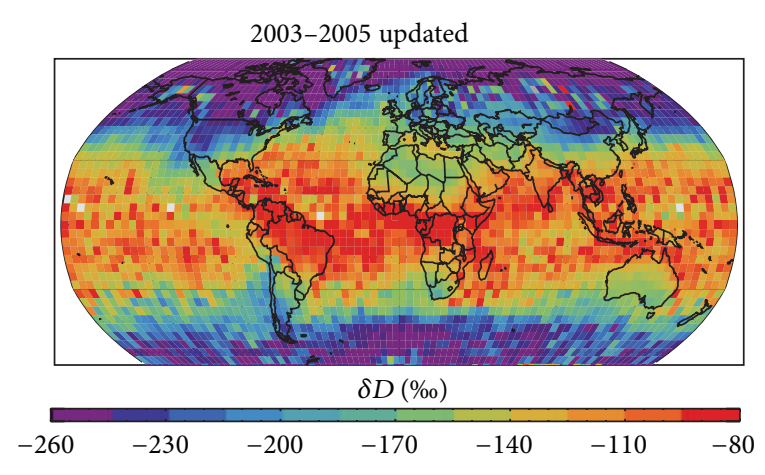

(a)

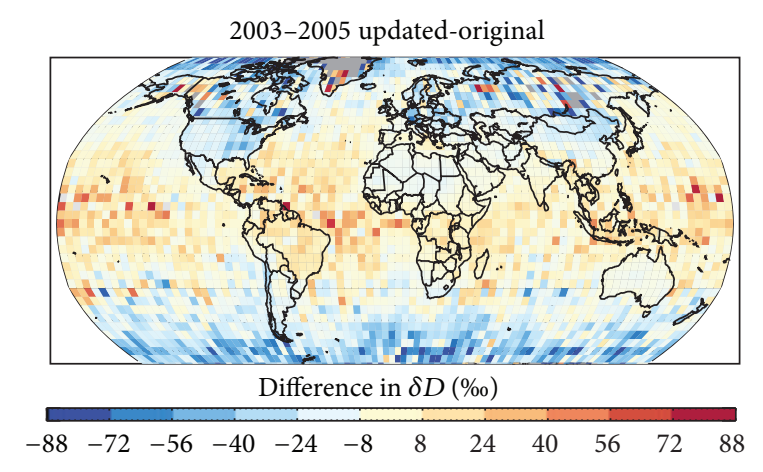

(b)

FiguRE 15: Top: updated 2003-2005 global average world map of $\delta$ D. Bottom: difference between the updated world map and the original world map from Frankenberg et al. [39]. This figure is adapted from Scheepmaker et al. [41].

isotopes measurements for examining shortcomings in the simulation of humidity in AGCMs.

\section{Future Prospects for Modeling and Validation}

Isotope-enabled AGCMs have been demonstrated to be valuable tools to study the global hydrological cycle in presentday climate. What does the future hold for isotope modeling and validation? This section synthesizes future prospects that have been discussed in the literature.

5.1. Overcome Intrinsic Limitations of AGCMs. Modeling stable isotopes in precipitation with an AGCM has some serious limitations that stem from limitations of the GCM itself, one example being the persistent biases in precipitation or temperature simulation $[3,22,26,29,44]$. Freerunning AGCMs solve dynamic equations using numerical approximations and the accuracy of simulation decreases significantly when there is a sharp boundary such as over the Tibetan Plateau [4]. It is expected that improved accuracy in simulating temperature and precipitation will lead to more accurate water isotopes simulations.

In addition, numerical inaccuracies in transport processes are collectively another obstacle to overcome. As Noone and Sturm [3] noted, water vapor abundance changes by at least four orders of magnitude in nature, and a numerical scheme must be able to resolve this range and three more orders of magnitude for $\delta \mathrm{D}$ in per mille. Artificial fractionation due to numerical errors persists even in some of most advanced isotope schemes [32]. These numerical inaccuracies lead to deficient simulation of moisture transport by largescale motions, by turbulent boundary layer motion, and by convective updrafts and downdrafts. Breakthroughs in numerical schemes could potentially result in more accurate simulations of water isotopes in AGCMs.

5.2. Long-Term Isotopic Measurements over the Oceans. Evaporation from the oceans is arguably the most important process in hydrological cycle and yet, it has never been a subject of systematic investigations [5]. Even up to now, there are still sparse ground-based measurements over the oceans and satellite measurements of water isotopes are often limited by weaker signal due to low reflected sunlight from the seawater. Conventional isotope ratio mass spectrometers (IRMS) have been used to measure isotope abundance for decades. However, one significant limitation of IRMS is its importability for field campaigns. Hoffmann et al. [1] suggested that sampling water vapor regularly at some wellselected sites over the oceans and analyzing the isotopes afterwards in laboratories could be extremely tedious because of the numerous collection, preparation, and transport of samples from fields to laboratories.

Could ships carry measurement equipment and automatically record isotope ratios as they traverse the oceans? Advances in laser spectroscopy made field measurements of water isotopes more feasible. Laser-based spectroscopic analyzers, being easily deployable for field measurements, could sample continuously and, thus, offer novel potential for improved measurement density. In addition, its precision and accuracy are almost comparable to that of the laboratory-based IRMS [45]. For example, new gas analyzers based on off-axis integrated cavity output spectroscopy (OAICOS) lasers are attractive instruments for long-term shipborne isotope measurements [46]. Furthermore, a network of laser based instrument could provide continuous in situ measurements of great frequency and accuracy. High-quality isotope measurements over the oceans would be extremely valuable for physical understanding and model developments and validation. As Helliker and Noone [45] put it, successful deployment of this new technology could potentially "revolutionize water isotope science."

5.3. Applications to Climatic Studies. There are some intriguing applications of isotope-enabled AGCMs to study climatic and dynamic phenomena. Isotopic studies have been done on storms [47], Arctic circulation [32], typhoons [48], African monsoon [14], ENSO [18], Madden-Julian oscillation [49], and Pacific-North American teleconnection pattern [50]. It is anticipated that, in the next few years, as we better understand the physics and chemistry of water isotopes and improve the 


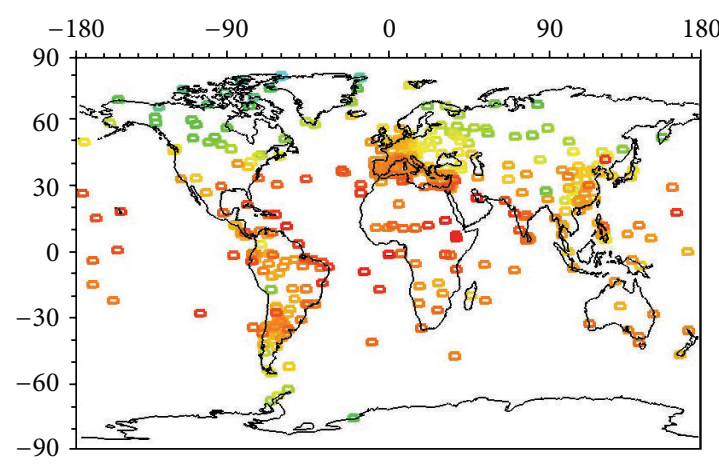

(a) GNIP

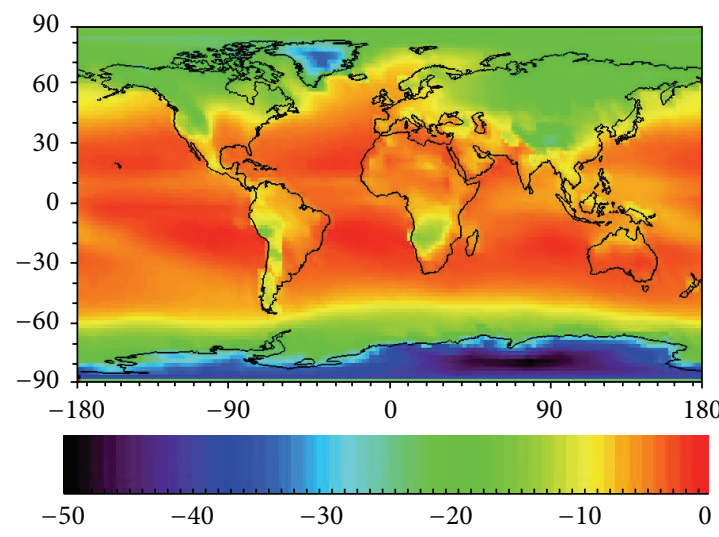

(c) GissE

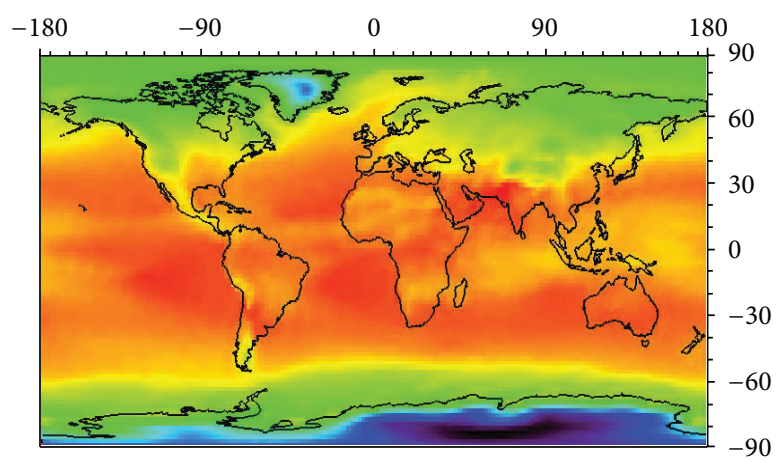

(b) ECHAM4

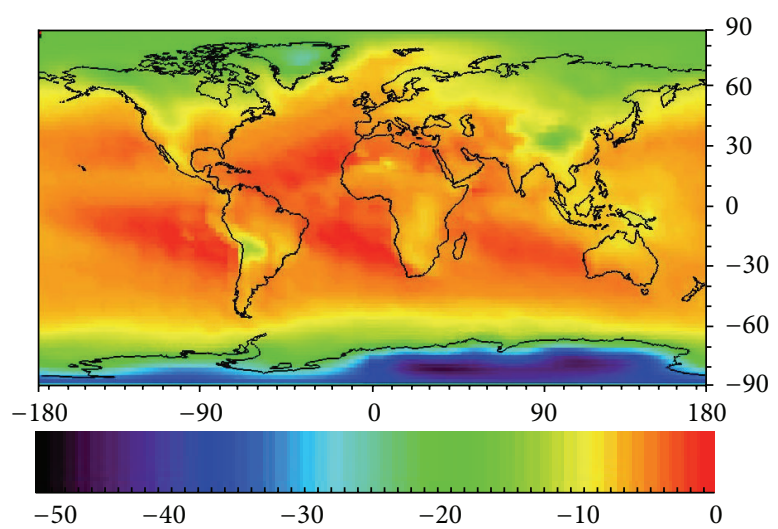

(d) MUGCM

FIGURE 16: Global pattern of long-term mean $\delta^{18} \mathrm{O}$ values of precipitation as derived from GNIP measurements (a), and the ECHAM4 (b), GissE (c), and MUGCM (d) simulations. All models are able to simulate the main characteristics of the global pattern such as latitude effect and continental effect. However, model results show some discrepancies on regions such as South Africa, Tibet Plateau, and Greenland. This figure is adapted from Werner and Gourcy [42].

numerical parameterizations of key hydrological processes, we will gain more insights into various climate phenomena through isotope-enabled AGCMs.

\section{Conclusions}

This paper reviews and synthesizes key advances in water isotope modeling. For surface evaporation, Cappa et al. [17] provided new isotopic molecular diffusivity ratios through experimental work. Coupled atmosphere-land surface models have been developed to improve simulations of evaporation from land surface. For condensation, a computationally demanding third-generation scheme could simulate complex cloud microphysical processes. For supersaturation, tuning parameters in the relation between supersaturation and condensation temperature result in better match between model outputs and measurements. For postcondensation processes, Lee and Fung [27] proposed a novel numerical model that adequately describes the interactions of raindrops and water vapor near the planetary boundary layer.

Yoshimura et al. [29] found that in lower-troposphere, a Rayleigh-type rainout effect dominates and, in the midtroposphere, the isotope signature is more affected by the mixing processes. Controlled experiments have shown that condensate evaporation does have a notable impact on the vertical profile of water isotopes. Noone and Simmonds [13] found that, typically, only $20 \sim 50 \%$ of $\delta^{18} \mathrm{O}$ variance could be explained by temperature changes, which implies that traditional interpretations of proxy records in paleoclimate studies need to be revised. A spectral nudging technique with reanalysis datasets has improved the simulation of temperature and $\delta^{18} \mathrm{O}$ at middle latitudes. Werner et al. [25] discovered that the simulations with the fine model resolution resolve some of the features over the ocean and result in a better agreement with GNIP datasets. Some coupled atmosphere-ocean models are able to trace water isotopes in both atmospheric and oceanic subsystems. They have been used to study climate phenomena that involve strong air-sea interactions.

The paper also reviews advances in model validation. Generally, ground-based measurements of water isotopes are of high precision and usually serve as benchmarks for the calibration of space-borne measurements. Although spaceborne measurements offer unprecedented global coverage, they have their known shortcomings and could not be regarded as absolute truth or perfect benchmark for AGCMs. During the two phases of SWING simulations and analyses, researchers have found some causes of the discrepancies 
among model outputs and measurements. This could lead to more model improvements in the future.

Future prospects for modeling and validation have been discussed. First, for more accurate simulations of water isotopes and the global hydrological cycle, the intrinsic limitations of AGCMs need to be overcome. Second, ships could carry measurement equipment and automatically record water isotope ratios as they traverse the oceans, thus providing unprecedented high-quality data for model validation. Third, we could gain more insights into various climatic and dynamic phenomena through isotope-enabled AGCMs.

\section{Conflict of Interests}

The author declares that there is no conflict of interests regarding the publication of this paper.

\section{Acknowledgments}

The author would like to thank Professors Alex Sessions, Yuk L. Yung, and Simona Bordoni for helpful discussions.

\section{References}

[1] G. Hoffmann, J. Jouzel, and V. Masson, "Stable water isotopes in atmospheric general circulation models," Hydrological Processes, vol. 14, no. 8, pp. 1385-1406, 2000.

[2] C. Sturm, Q. Zhang, and D. Noone, "An introduction to stable water isotopes in climate models: benefits of forward proxy modelling for paleoclimatology," Climate of the Past, vol. 6, no. 1, pp. 115-129, 2010.

[3] D. Noone and C. Sturm, "Comprehensive dynamical models of global and regional water isotope distributions," in Isoscapes, J. B. West, G. J. Bowen, T. E. Dawson, and K. P. Tu, Eds., pp. 195219, Springer, Amsterdam, The Netherlands, 2010.

[4] T. Yao, V. Masson-Delmotte, J. Gao et al., "A review of climatic controls on $\delta^{18} \mathrm{O}$ in precipitation over the Tibetan Plateau: observations and simulations," Reviews of Geophysics, vol. 51, no. 4, pp. 525-548, 2013.

[5] W. Dansgaard, "Stable isotopes in precipitation," Tellus, vol. 16, no. 4, pp. 436-468, 1964.

[6] J. Hoefs, Stable Isotope Geochemistry, Springer, Berlin, Germany, 2009.

[7] H. Craig, "Isotopic variations in meteoric waters," Science, vol. 133, no. 3465, pp. 1702-1703, 1961.

[8] H. Craig, "Standard for reporting concentrations of deuterium and oxygen-18 in natural waters," Science, vol. 133, no. 3467, pp. 1833-1834, 1961.

[9] K. Froehlich, J. J. Gibson, and P. Aggarwal, Deuterium Excess in Precipitation and Its Climatological Significance, International Atomic Energy Agency, Ontario, Canada, 2002.

[10] J. R. Gat, "Oxygen and hydrogen isotopes in the hydrologic cycle," Annual Review of Earth and Planetary Sciences, vol. 24, pp. 225-262, 1996.

[11] S. Joussaume, R. Sadourny, and J. Jouzel, "A general circulation model of water isotope cycles in the atmosphere," Nature, vol. 311, no. 5981, pp. 24-29, 1984.

[12] H. Craig and L. I. Gordon, "Deuterium and oxygen 18 variations in the ocean and marine atmosphere," in Proceedings of the
Stable Isotopes in Oceanographic Studies and Paleotemperatures, Spoleto, Italy, 1965.

[13] D. Noone and I. Simmonds, "Associations between $\delta 18 \mathrm{O}$ of water and climate parameters in a simulation of atmospheric circulation for 1979-95," Journal of Climate, vol. 15, no. 22, pp. 3150-3169, 2002.

[14] C. Risi, Analysis and Modeling of the Siganture of the Variations of the Tropical Climate in the Isotopic Composition of Water (O18 et D), University of Paris VI, Paris, France, 2009.

[15] J. Jouzel, G. Hoffmann, R. D. Koster, and V. Masson, "Water isotopes in precipitation: data/model comparison for presentday and past climates," Quaternary Science Reviews, vol. 19, no. 1-5, pp. 363-379, 2000.

[16] L. Merlivat and J. Jouzel, "Global climatic interpretation of the deuterium-oxygen 16 relationship for precipitation," Journal of Geophysical Research, vol. 84, no. 8, pp. 5029-5033, 1979.

[17] C. D. Cappa, M. B. Hendricks, D. J. DePaolo, and R. C. Cohen, "Isotopic fractionation of water during evaporation," Journal of Geophysical Research: Atmospheres, vol. 108, no. D16, p. 4525, 2003.

[18] J. C. Tindall, P. J. Valdes, and L. C. Sime, "Stable water isotopes in HadCM3: isotopic signature of El Niño-Southern oscillation and the tropical amount effect," Journal of Geophysical Research D: Atmospheres, vol. 114, no. 4, Article ID D04111, 2009.

[19] B. Haese, M. Werner, and G. Lohmann, "Stable water isotopes in the coupled atmosphere-land surface model ECHAM5JSBACH," Geoscientific Model Development, vol. 6, no. 5, pp. 1463-1480, 2013.

[20] I. Aleinov and G. A. Schmidt, "Water isotopes in the GISS ModelE land surface scheme," Global and Planetary Change, vol. 51, no. 1-2, pp. 108-120, 2006.

[21] K. Yoshimura, S. Miyazaki, S. Kanae, and T. Oki, "IsoMATSIRO, a land surface model that incorporates stable water isotopes," Global and Planetary Change, vol. 51, no. 1-2, pp. 90107, 2006.

[22] J.-E. Lee, I. Fung, D. J. DePaolo, and C. C. Henning, "Analysis of the global distribution of water isotopes using the NCAR atmospheric general circulation model," Journal of Geophysical Research D: Atmospheres, vol. 112, no. 16, Article ID D16306, 2007.

[23] J. Jouzel and L. Merlivat, "Deuterium and oxygen 18 in precipitation: modeling of the isotopic effects during snow formation," Journal of Geophysical Research: Atmospheres, vol. 89, no. D7, pp. 11749-11757, 1984.

[24] C. Risi, S. Bony, F. Vimeux, and J. Jouzel, "Water-stable isotopes in the LMDZ4 general circulation model: model evaluation for present-day and past climates and applications to climatic interpretations of tropical isotopic records," Journal of Geophysical Research D: Atmospheres, vol. 115, no. 24, Article ID D24123, 2010.

[25] M. Werner, P. M. Langebroek, T. Carlsen, M. Herold, and G. Lohmann, "Stable water isotopes in the ECHAM5 general circulation model: toward high-resolution isotope modeling on a global scale," Journal of Geophysical Research D: Atmospheres, vol. 116, no. 15, Article ID D15109, 2011.

[26] R. Mathieu, D. Pollard, J. E. Cole, J. W. C. White, R. S. Webb, and S. L. Thompson, "Simulation of stable water isotope variations by the GENESIS GCM for modern conditions," Journal of Geophysical Research D: Atmospheres, vol. 107, no. 4, 2002.

[27] J.-E. Lee and I. Fung, "Amount effect' of water isotopes and quantitative analysis of post-condensation processes," Hydrological Processes, vol. 22, no. 1, pp. 1-8, 2008. 
[28] G. A. Schmidt, G. Hoffmann, D. T. Shindell, and Y. Hu, "Modeling atmospheric stable water isotopes and the potential for constraining cloud processes and stratosphere-troposphere water exchange," Journal of Geophysical Research D: Atmospheres, vol. 110, no. 21, Article ID D21314, 2005.

[29] K. Yoshimura, C. Frankenberg, J. Lee, M. Kanamitsu, J. Worden, and T. Röckmann, "Comparison of an isotopic atmospheric general circulation model with new quasi-global satellite measurements of water vapor isotopologues," Journal of Geophysical Research D: Atmospheres, vol. 116, no. 19, Article ID D19118, 2011.

[30] J. S. Wright, A. H. Sobel, and G. A. Schmidt, "Influence of condensate evaporation on water vapor and its stable isotopes in a GCM," Geophysical Research Letters, vol. 36, no. 12, Article ID L12804, 2009.

[31] G. A. Schmidt, A. N. LeGrande, and G. Hoffmann, "Water isotope expressions of intrinsic and forced variability in a coupled ocean-atmosphere model," Journal of Geophysical Research D: Atmospheres, vol. 112, no. 10, Article ID D10103, 2007.

[32] K. Yoshimura, M. Kanamitsu, D. Noone, and T. Oki, "Historical isotope simulation using Reanalysis atmospheric data," Journal of Geophysical Research D: Atmospheres, vol. 113, no. 19, 2008.

[33] C. Risi, D. Noone, J. Worden et al., "Process-evaluation of tropospheric humidity simulated by general circulation models using water vapor isotopologues: 1 . Comparison between models and observations," Journal of Geophysical Research: Atmospheres, vol. 117, no. D5, p. D05303, 2012.

[34] E. G. Nisbet, E. J. Dlugokencky, and P. Bousquet, "Methane on the rise-again," Science, vol. 343, no. 6170, pp. 493-495, 2014.

[35] I.A.E.A. (International Atomic Energy Agency), "Global Network of Isotopes in Precipitation (GNIP)," IAEA, 2013.

[36] K. Rozanski, L. Araguás-Araguás, and R. Gonfiantini, "Isotopic patterns in modern global precipitation," in Climate Change in Continental Isotopic Records, pp. 1-36, American Geophysical Union, 1993.

[37] D. Wunch, G. C. Toon, J.-F. L. Blavier et al., "The total carbon column observing network," Philosophical Transactions of the Royal Society A: Mathematical, Physical and Engineering Sciences, vol. 369, no. 1943, pp. 2087-2112, 2011.

[38] M. Schneider, K. Yoshimura, F. Hase, and T. Blumenstock, "The ground-based FTIR network's potential for investigating the atmospheric water cycle," Atmospheric Chemistry and Physics, vol. 10, no. 7, pp. 3427-3442, 2010.

[39] C. Frankenberg, K. Yoshimura, T. Warneke et al., "Dynamic processes governing lower-tropospheric $\mathrm{HDO} / \mathrm{H} 2 \mathrm{O}$ Ratios as Observed from Space and Ground," Science, vol. 325, no. 5946, pp. 1374-1377, 2009.

[40] J. Worden, K. Bowman, D. Noone et al., "Tropospheric Emission Spectrometer observations of the tropospheric $\mathrm{HDO} / \mathrm{H}_{2} \mathrm{O}$ ratio: estimation approach and characterization," Journal of Geophysical Research D: Atmospheres, vol. 111, no. 16, Article ID D16309, 2006.

[41] R. A. Scheepmaker, C. Frankenberg, A. Galli et al., "Improved water vapour spectroscopy in the $4174-4300 \mathrm{~cm}^{-1}$ region and its impact on SCIAMACHY $\mathrm{HDO} / \mathrm{H}_{2} \mathrm{O}$ measurements," Atmospheric Measurement Techniques, vol. 6, no. 4, pp. 879-894, 2013.

[42] M. Werner and L. Gourcy, “The Stable Water Isotope Intercomparison Group (SWING): first results of a new model intercomparison study," in Proceedings of the American Geophysical Union Fall Meeting (AGU '04), 2004.

[43] C. Risi, D. Noone, J. Worden et al., "Process-evaluation of tropospheric humidity simulated by general circulation models using water vapor isotopic observations: 2. Using isotopic diagnostics to understand the mid and upper tropospheric moist bias in the tropics and subtropics," Journal of Geophysical Research D: Atmospheres, vol. 117, no. 5, Article ID D05304, 2012.

[44] X. Zhang, Z. Sun, H. Guan, H. Wu, and Y. Huang, "GCM simulations of stable isotopes in the water cycle in comparison with GNIP observations over East Asia," Acta Meteorologica Sinica, vol. 26, no. 4, pp. 420-437, 2012.

[45] B. Helliker and D. Noone, "Novel approaches for monitoring of water vapor isotope ratios: plants, lasers and satellites," in Isoscapes, J. B. West, G. J. Bowen, T. E. Dawson, and K. P. Tu, Eds., pp. 71-88, Springer, Amsterdam, The Netherlands, 2010.

[46] G. Lis, L. I. Wassenaar, and M. J. Hendry, "High-precision laser spectroscopy $\mathrm{D} / \mathrm{H}$ and $18 \mathrm{O} / 16 \mathrm{O}$ measurements of microliter natural water samples," Analytical Chemistry, vol. 80, no. 1, pp. 287-293, 2008.

[47] S. Gedzelman, J. J. Lawrence, M. Gamache et al., "Probing hurricanes with stable isotopes of rain and water vapor," Monthly Weather Review, vol. 131, no. 6, pp. 1112-1127, 2003.

[48] H. Fudeyasu, K. Ichiyanagi, A. Sugimoto et al., "Isotope ratios of precipitation and water vapor observed in typhoon Shanshan," Journal of Geophysical Research D: Atmospheres, vol. 113, no. 12, Article ID D12113, 2008.

[49] N. Kurita, D. Noone, C. Risi, G. A. Schmidt, H. Yamada, and K. Yoneyama, "Intraseasonal isotopic variation associated with the Madden-Julian Oscillation," Journal of Geophysical Research D: Atmospheres, vol. 116, no. 24, Article ID D24101, 2011.

[50] Z. Liu, K. Yoshmura, G. J. Bowen, and J. M. Welker, "PacificNorth American teleconnection controls on precipitation isotopes $(\rho 18 \mathrm{O})$ across the Contiguous United States and Adjacent Regions: a GCM-based analysis," Journal of Climate, vol. 27, no. 3, pp. 1046-1061, 2014.

[51] T. Coplen, A. Herczeg, and C. Barnes, "Isotope engineeringusing stable isotopes of the water molecule to solve practical problems," in Environmental Tracers in Subsurface Hydrology, P. Cook and A. Herczeg, Eds., pp. 79-110, Springer, New York, NY, USA, 2000.

[52] SAHRA, Sustainability of semi-Arid Hydrology and Riparian Areas, Isotopes: Oxygen, Arizona, Ariz, USA, 2005.

[53] Earth Observatory, Paleoclimatology: The Oxygen Balance, 2005.

[54] K. McGuire and J. McDonnell, "Stable isotope tracers in watershed hydrology," in Stable Isotopes in Ecology and Environmental Scienc, pp. 334-374, Blackwell, Oxford, UK, 2008.

[55] M. Herold, Modelling Stable Isotopes in the Eemian and Holocene Hydrological Cycles, Department of Physics and Electrical Engineering, Bremen University, Bremen, Germany, 2011.

[56] V. Masson-Delmotte, S. Hou, A. Ekaykin et al., "A review of antarctic surface snow isotopic composition: observations, atmospheric circulation, and isotopic modeling," Journal of Climate, vol. 21, no. 13, pp. 3359-3387, 2008.

[57] M. C. McCarthy, K. A. Boering, T. Rahn et al., “The hydrogen isotopic composition of water vapor entering the stratosphere inferred from high-precision measurements of $\delta \mathrm{D}-\mathrm{CH}_{4}$ and $\delta \mathrm{D}-\mathrm{H}_{2}$," Journal of Geophysical Research: Atmospheres, vol. 109, no. D7, 2004.

[58] G. A. Schmidt, R. Ruedy, J. E. Hansen et al., "Present-day atmospheric simulations using GISS ModelE: comparison to in situ, satellite, and reanalysis data," Journal of Climate, vol. 19, no. 2, pp. 153-192, 2006.

[59] F. Hourdin, I. Musat, S. Bony et al., "The LMDZ4 general circulation model: climate performance and sensitivity to 
parametrized physics with emphasis on tropical convection," Climate Dynamics, vol. 27, no. 7-8, pp. 787-813, 2006.

[60] P. F. Bernath, C. T. McElroy, M. C. Abrams et al., "Atmospheric chemistry experiment (ACE): mission overview," Geophysical Research Letters, vol. 32, no. 15, 2005.

[61] C. Frankenberg, D. Wunch, G. Toon et al., "Water vapor isotopologue retrievals from high-resolution GOSAT shortwave infrared spectra," Atmospheric Measurement Techniques, vol. 6, no. 2, pp. 263-274, 2013.

[62] H. Herbin, D. Hurtmans, C. Clerbaux, L. Clarisse, and P.-F. Coheur, "H216O and HDO measurements with IASI/MetOp," Atmospheric Chemistry and Physics, vol. 9, no. 24, pp. 94339447, 2009.

[63] V. I. Zakharov, R. Imasu, K. G. Gribanov, G. Hoffmann, and J. Jouzel, "Latitudinal distribution of the deuterium to hydrogen ratio in the atmospheric water vapor retrieved from IMG/ADEOS data," Geophysical Research Letters, vol. 31, no. 12, Article ID L12104, 2004.

[64] J. Steinwagner, M. Milz, T. von Clarmann et al., "HDO measurements with MIPAS," Atmospheric Chemistry and Physics, vol. 7, no. 10, pp. 2601-2615, 2007.

[65] V. H. Payne, D. Noone, A. Dudhia, C. Piccolo, and R. G. Grainger, "Global satellite measurements of HDO and implications for understanding the transport of water vapour into the stratosphere," Quarterly Journal of the Royal Meteorological Society, vol. 133, no. 627, pp. 1459-1471, 2007.

[66] J. Worden, D. Noone, and K. Bowman, "Importance of rain evaporation and continental convection in the tropical water cycle," Nature, vol. 445, no. 7127, pp. 528-532, 2007. 

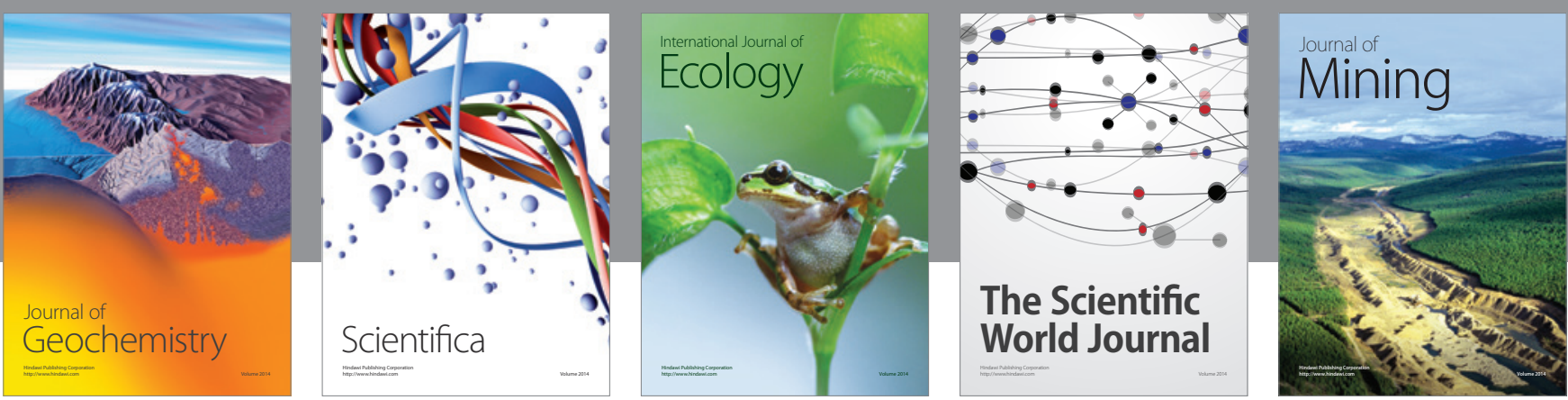

The Scientific World Journal
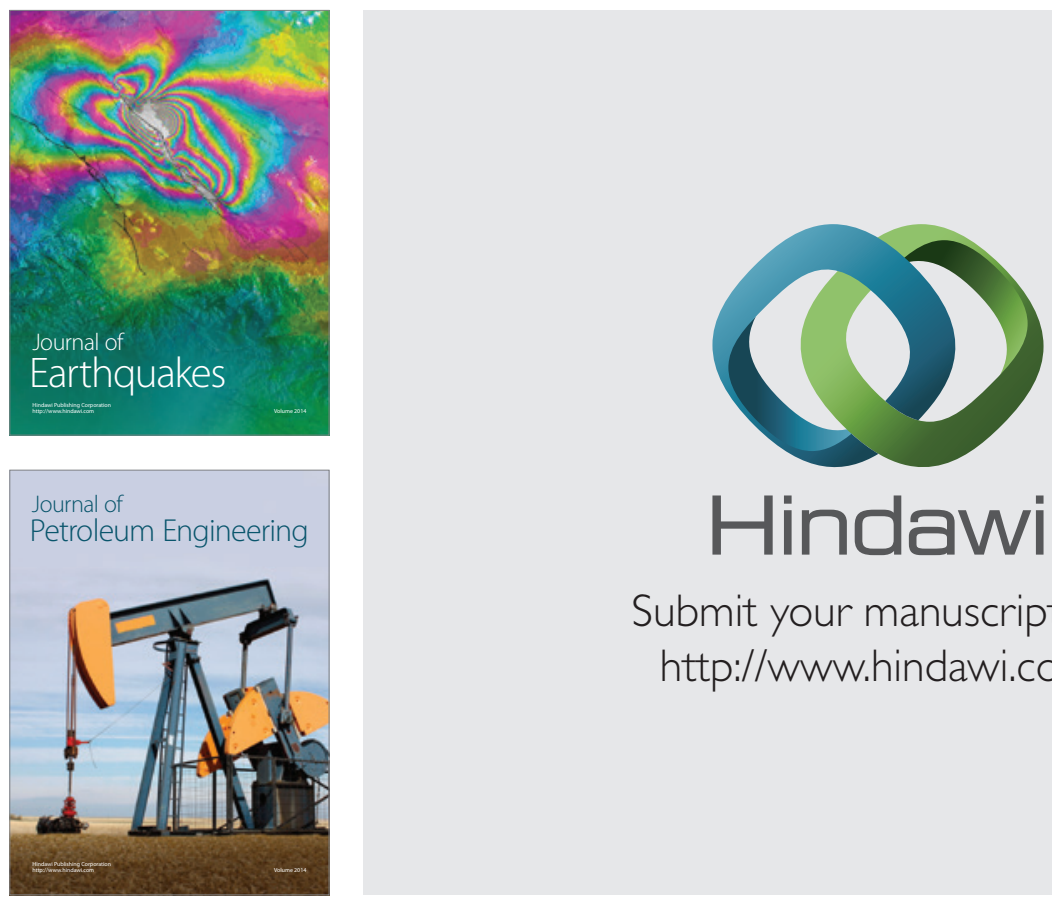

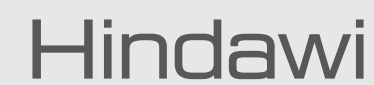

Submit your manuscripts at

http://www.hindawi.com
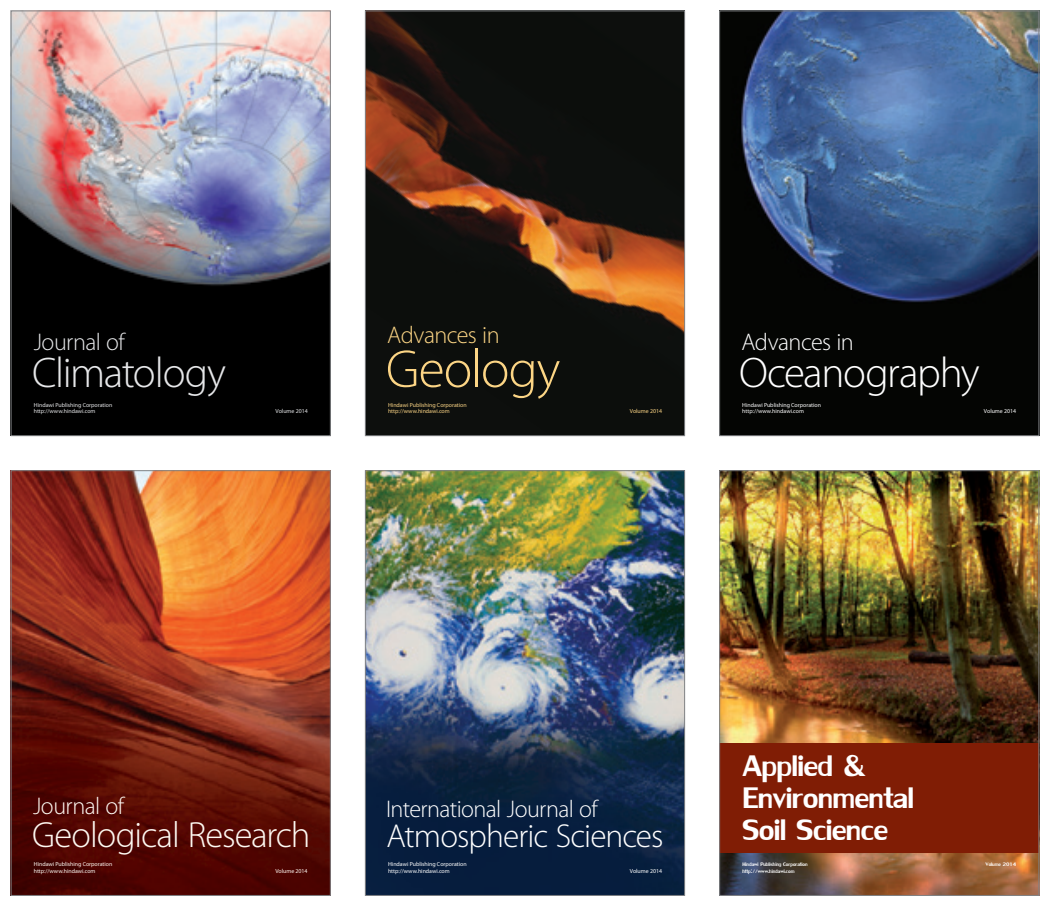
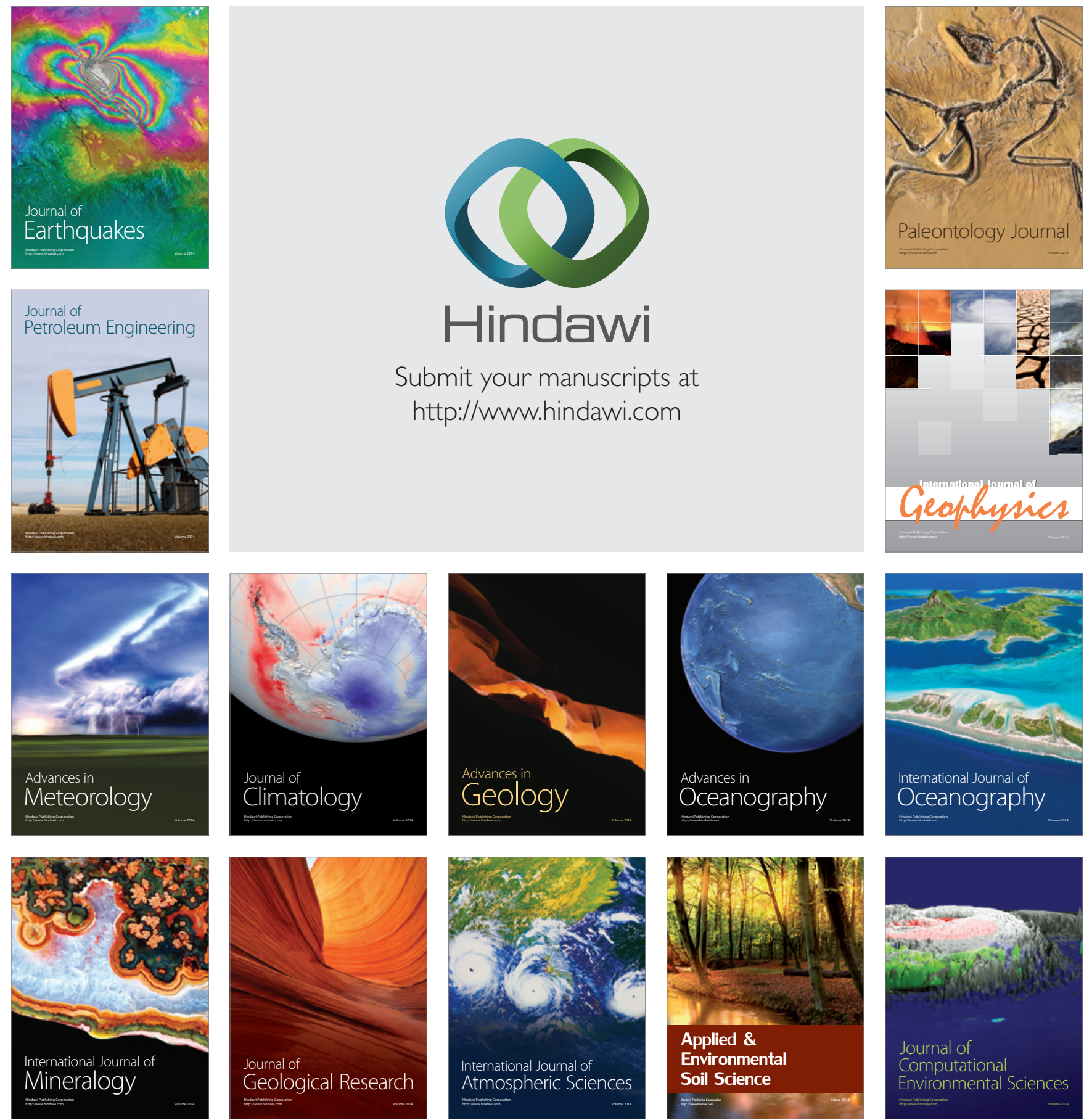